\title{
In Quest of Pathognomonic/Endophenotypic Markers of Attention Deficit Hyperactivity Disorder (ADHD): Potential of EEG-Based Frequency Analysis and ERPs to Better Detect, Prevent and Manage ADHD
}

This article was published in the following Dove Press journal:

Medical Devices: Evidence and Research

\author{
Priya Miranda (D) \\ Christopher D Cox ${ }^{2}$ \\ Michael Alexander ${ }^{1}$ \\ Slav Danev ${ }^{3}$ \\ Jonathan RT Lakey' \\ 'Department of Surgery and Biomedical \\ Engineering, University of California \\ Irvine, Irvine, California, USA; \\ ${ }^{2}$ Department of Neurology, David Geffen \\ School of Medicine, University of \\ California, Los Angeles, California, USA; \\ ${ }^{3}$ Medeia Inc, Santa Barbara, CA, USA
}

\begin{abstract}
Attention deficit hyperactivity disorder (ADHD) is a chronic heritable developmental delay psychiatric disorder requiring chronic management, characterized by inattention, hyperactivity, hyperkinectivity and impulsivity. Subjective clinical evaluation still remains crucial in its diagnosis. Discussed are two key aspects in the "characterizing ADHD" and on the quest for objective "pathognomonic/endophenotypic diagnostic markers of ADHD". The first aspect briefly revolves around issues related to identification of pathognomonic/endophenotypic diagnostic markers in ADHD. Issues discussed include changes in ADHD definition, remission/persistence and overlapping-symptoms cum sharedheritability with its co-morbid cross-border mental disorders. The second aspect discussed is neurobiological and EEG-based studies on ADHD. Given the neurobiological and temporal aspects of ADHD symptoms the electroencephalograph (EEG) like NeuralScan by Medeia appears as an appropriate tool. The EEGs appropriateness is further enhanced when coupled with suitable behavior/cognitive/motor/psychological tasks/paradigms yielding EEG-based markers like event-related-potential (ERPs like P3 amplitudes and latency), reaction time variability (RTV), Theta:Beta ratio (TBR) and sensorimotor rhythm (SMR). At present, these markers could potentially help in the neurobiological characterization of ADHD and either help in identifying or lay the groundwork for identifying pathognomonic and/or endophenotypic EEG-based markers enabling its diagnosis, treatment and management.
\end{abstract}

Keywords: ADHD, EEG, event related potential, reaction time

\section{Introduction}

While attention deficit hyperactivity disorder (ADHD) carries the distinction of being among the most well-researched mental disorders still challenges remain regarding its diagnosis, management and treatment. For instance, to date diagnosis is based on subjective clinical examination using standard questionnaires and tests that capture impairments in behavior and cognition. ${ }^{1-7}$

As ADHD traits (inattention, hyperactivity, hyperkinectivity and impulsivity) have both a neurobiological and temporal aspect state-of-the-art electroencephalography (EEG) machines like NeuralScan by Medeia (Figure 1) with its easy-to-wear reusable 10/20 system EEG caps, user/clinician-friendly software and cloud-based reporting make neurobiological characterization of ADHD possible. However, while EEG-based confirmation of ADHD has received FDA approval, it has yet to be
Correspondence: Jonathan RT Lakey Department of Surgery, 333 City Blvd West, Suite 1600, Orange, CA 92868 USA

Tel + I-949-824-8022

Fax $+|-7| 4-456-6 \mid 88$

Email jlakey@uci.edu 


\section{A NeuralScan EEG cap-10/20 system}

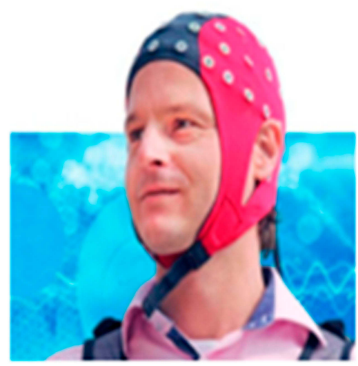

Eyes Open: Posterlor Peak Frequency: $24 / \mathrm{HL}$

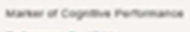

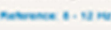

Eyes Open: Thereveta Ratio: 0.35

cones

s.r.t...

Eyes Open: Central Asymmetry: $\quad 1.48 \%$

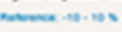

Eyes Closed: Posterior Peak Frequency: $10 \mathrm{He}$

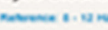

Eyes Open / Closed Alpha Ratios: 0.87

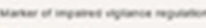

B Sample Results of Resting EEG studies (Eyes Open and Eyes Closed) and Theta/Beta Ratio (TBR) carried out with NeuralScan by Medeia

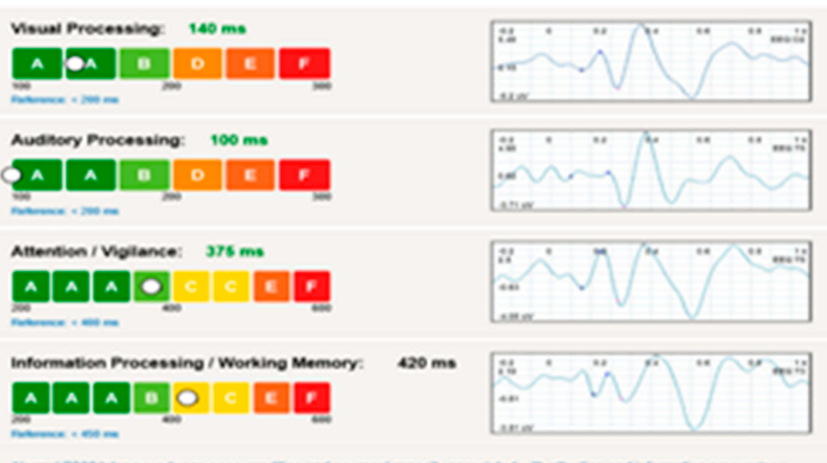

C Sample Results of studies evaluating Visual and Auditory processing, Working Memory and Attention with the paradigms that elicit them carried out with NeuralScan by Medeia

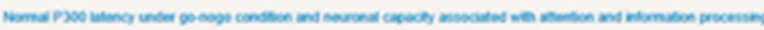

D Sample Results of studies evaluating TBR, Visual and Auditory processing, Working Memory and Attention, Reaction Time (RT) and Reaction Time Variability (RTV) using by Medeia

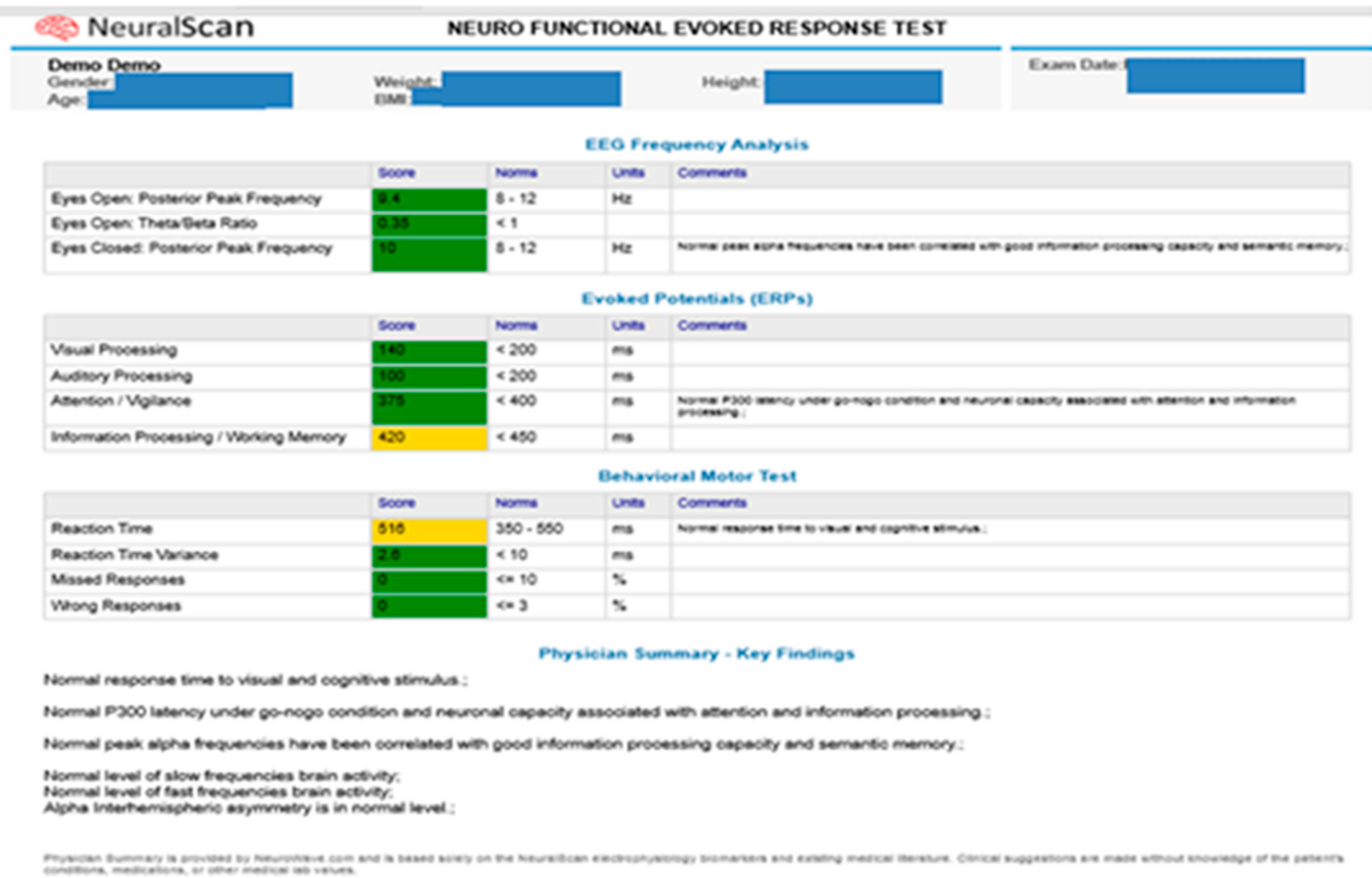

Figure I EEG-based frequency analysis using (A) NeuralScan by Medeia showing demo results of: (B) Resting EEG (Eyes Open and Eyes Closed) and Theta/Beta ratio, (C) Visual and Auditory processing, Working Memory and Attention and (D) Theta/Beta ratio, Visual and Auditory processing, Working Memory, Attention Reaction Time (RT) and Reaction Time Variability (RTV). 
approved in instances where the clinical diagnosis of ADHD is negative, the aim being to prevent overdiagnosis and misdiagnosis. ${ }^{8}$ Recent features like quantitative electroencephalogram (qEEG) and low-resolution brain electromagnetic tomography (LORETA) have added both a power and spatial component to EEG analysis. ${ }^{9-11}$ With these new features, one can measure, capture and record from Theta:Beta ratio (TBR) to a whole range of EEGbased frequency analysis (alpha, $\alpha$, beta, $\beta$, theta, $\theta$, delta, $\delta$, gamma, $\gamma, \mathrm{mu}$, sensorimotor rhythm (SMR)) to eventrelated-potential (ERPs) components (P1, N1, P2, N2, P3, $\mathrm{N} 3, \mathrm{ERN}, \mathrm{Pe}, \mathrm{CNV}, \mathrm{RT}$, amplitudes and latency) to reaction time variability (RTV) to power and source analysis. Furthermore depending on the paradigms and tasks used to elicit these ERPs one can now achieve better neurobiological, behavioral and psychological characterization and guide management of ADHD. Thus, EEG machines like NeuralScan are fast becoming potential pathognomonic diagnostic tools.

Clinicians could easily study and assess

(a) Neurobiological and EEG-based risk factors of cognitive impairment, hyperactivity and attention that will either be potential markers or modifiable traits,

(b) responder and non-responders to treatment via medication/behavioral therapy/neurofeedback,

(c) heritable brainwave alterations exclusive to ADHD or shared with it co-morbid psychiatric disorders and

(d) tailor treatment.

Taken together the EEG-based findings could in turn add enormous value in the quest for brain-based pathognomonic and endophenotypic markers of ADHD. The benefit of endophenotypic markers of ADHD would be that diagnosis would be more objective and less symptom-based especially in light of symptom overlaps with other crossborder co-morbid mental disorders. However, endophenotyping ADHD comes with its own challenge is that ADHD also shares heritable traits with some of its co-morbid mental disorders. With this in mind we sought to consider together I) challenges in identifying markers of ADHD, current II) neurobiology and III) EEG-based aspects on ADHD in the hope of either identifying or laying the framework for identification of potential pathognomonic/ endophenotypic markers of ADHD.

\section{Challenges in Identifying Endophenotypic/Pathognomonic Markers of ADHD Changes in Diagnostic Criteria}

Changes in diagnostic criteria impact on: prevalence, incidence, conversion and remission rates, comparison across studies and long-term follow-up studies. The nosology of ADHD has changed from the "incapacity to attend" to a "Neurodevelopmental Neurocognitive Disorder". 12-15 Developments in neuropsychology, neuroimaging, epidemiology, genetics, and pathophysiology contributed to Diagnostic and Statistical Manual for Mental Disorders (DSM) DSM-VI/DSM-VI-TR's classification of ADHD as ADHD with inattention (ADHD-I), hyperactivity (ADHD-H), and combined (ADHD-C) subtypes. ${ }^{5}$ Barkley further described ADHD.

as a disorder of executive dysregulation (in behavioral inhibition, working memory, motivation, and motor control) rather than simply of attention and hyperactivity ${ }^{16}$

Barkley worked to ensure it was distinct from concentration deficit disorder (CDD). ${ }^{16-19}$ Further developments in molecular biology, psychometrics, and cognitive and affective neurosciences led to ADHD being classified under "Neurodevelopmental Disorders" and "Neurocognitive Disorders" in DSM-V requiring symptoms to be present in two or more environments. ${ }^{6}$ Based on the current definition of ADHD its prevalence is $2.2 \%$ in children which translates to $1: 45$ children and $2.8 \%$ in adults, i.e. $1: 36$ adults. $50-65 \%$ of childhood ADHD persists into adulthood with the persistence rate of childhood ADHD being $47.4 \%$. The higher adult prevalence rate seen is a reflection of conversion of children who were originally below the diagnostic thresholds and self-reported or new cases of adult ADHD. ${ }^{20-22}$

\section{Overlapping Symptoms of Cross-Border Cum Co-Morbid Mental Disorders}

While symptoms/behavior manifesting as a spectrum of hues, tones, tints and shades, were originally used to frame the diagnostic criteria they have also added to the confusion due to symptom-sharing between cross-border cum comorbid mental disorders. ${ }^{6,7,23,24} 80 \%$ of individuals with adult ADHD have at least one other co-morbid condition. $^{23-27}$ While the general consensus is to treat the dominant functionally impairing illness the overlapping symptoms make clear-cut diagnosis, treatment and determination of the burden of disease challenging ${ }^{28-31}$ Figure $2 \mathrm{~A}$ 


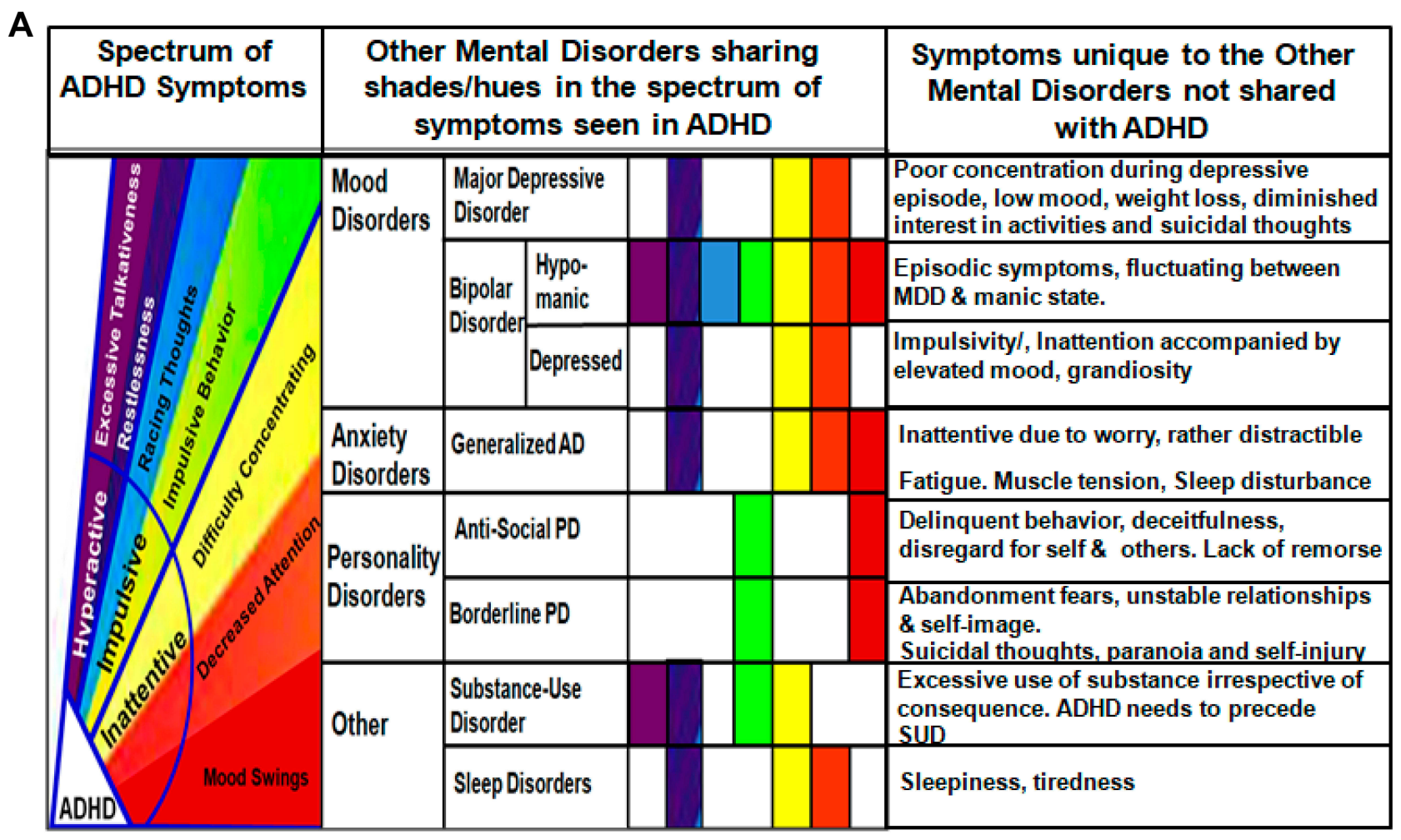

B Individuals (\%) with Other Mental Disorders with ADHD ( $n=349)$

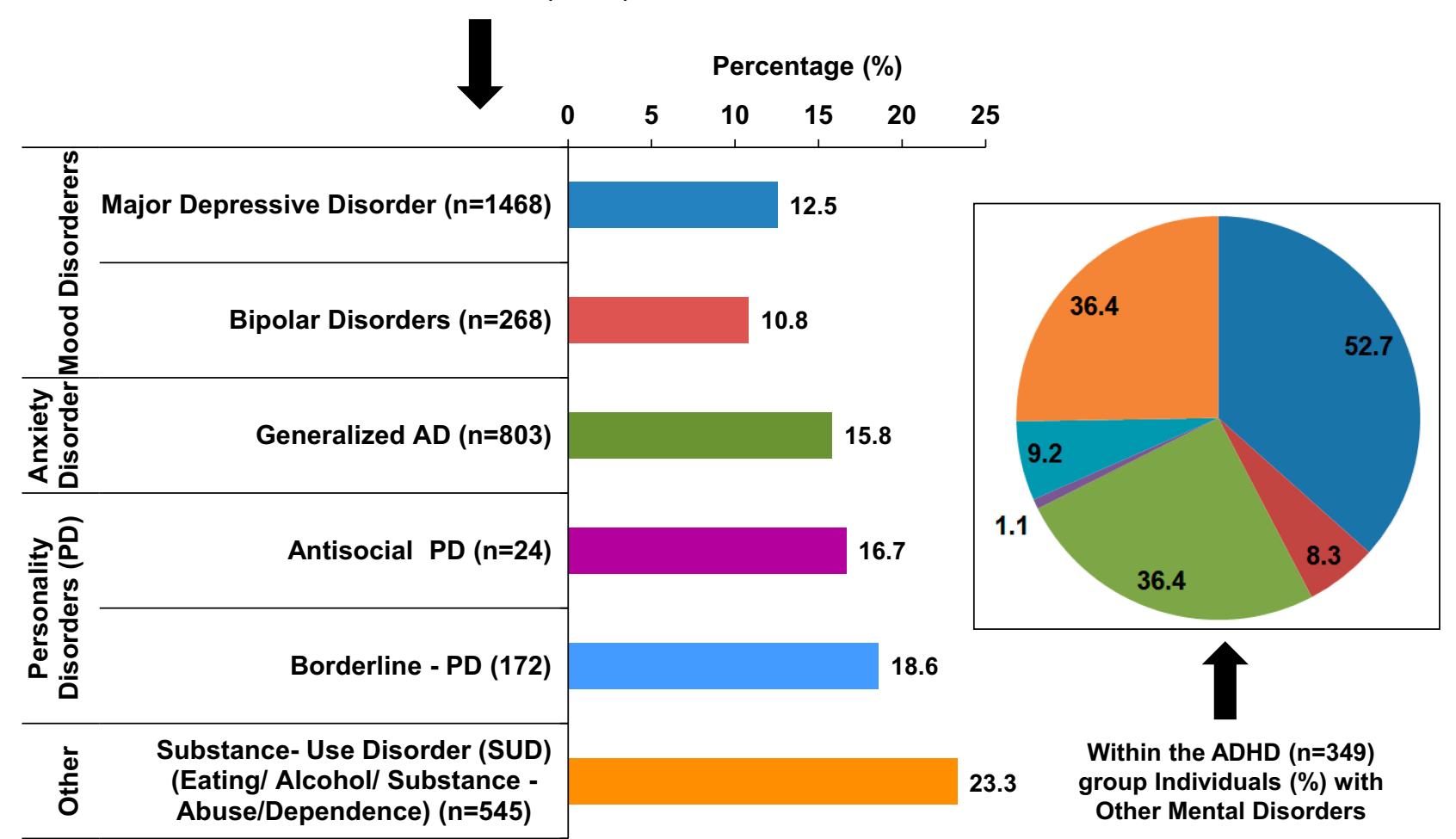

Figure 2 (A) ADHD and its cross-border co-morbidities: Illustration of symptom sharingandsymptoms unique. ${ }^{6,7}$ Percentage of Individuals with ADHD and selected symptom sharing (cross-border) psychiatric comorbidities (32). 
provides an illustration of symptoms shared by and symptoms that distinguish ADHD and other mental disorders. ${ }^{6,7}$ Figure 2B presents the results of a multinational crosssectional study in Europe to estimate the prevalence of ADHD in adult outpatient psychiatric care facilities. Out of $\mathrm{n}=2284$ individuals included in the study, 349 had ADHD $\left(17.4 \%, n=2009\right.$ screened using DSM-V). ${ }^{32}$ Within the ADHD subgroup (pie diagram) major depressive disorder (MDD), generalized anxiety disorder (generalized AD) and substance use disorder (SUD) were the most common comorbidities. Study results of the Regional ADHD Registry database at 18 tertiary care ADHD centers $(n=2861)$ in Italy between 2011 and 2016 period were, 67\% $(n=1919)$ had ADHD, among whom 34\% $(n=650)$ had ADHD alone and the remaining had $\mathrm{ADHD}+\geq 1$ mental health co-morbidity (learning disorders/sleep disorders/oppositional defiant disorder/anxiety disorders). ${ }^{33}$ The implications for neurobiological and EEG-based studies on ADHD are overlapping symptoms that could extend to overlaps in neurobiological and EEG patterns.

\section{Heritability of ADHD and Shared Heritability of Its Co-Morbidities}

Compounding the issue is the heritability and at times shared heritability of both ADHD and its co-morbidities and that ADHD is a heterogenous disorder with many subtypes (ADHD-I, ADHD-H, and ADHD-C). Genetic studies on ADHD include a) family, b) twin, c) candidate genes, d)genome-wide approaches (GWAS), e) copy number variations (CNV), f) environmental risks and $\mathrm{g}$ ) endophenotypes. $^{34-47}$ Siblings of ADHD probands are at 9-times greater risk of ADHD with twins both monozygotic: $M Z$ and dizygotic: DZ, sharing $100 \%$ and $50 \%$ genetic inheritance, respectively, as well as environmental exposure exhibit a heritability of ADHD of $\sim 75 \%$. $^{34-36}$

A GWAS study worth mentioning in detail is one carried out by the Brain Consortium (Figure 3) to quantify the degree of overlap of genetic risk factors involved in 10 psychiatric and 15 neurological disorders also looking at 17 behaviour-cognitive phenotypes among 265,218 patients and 784,643 control participants (total

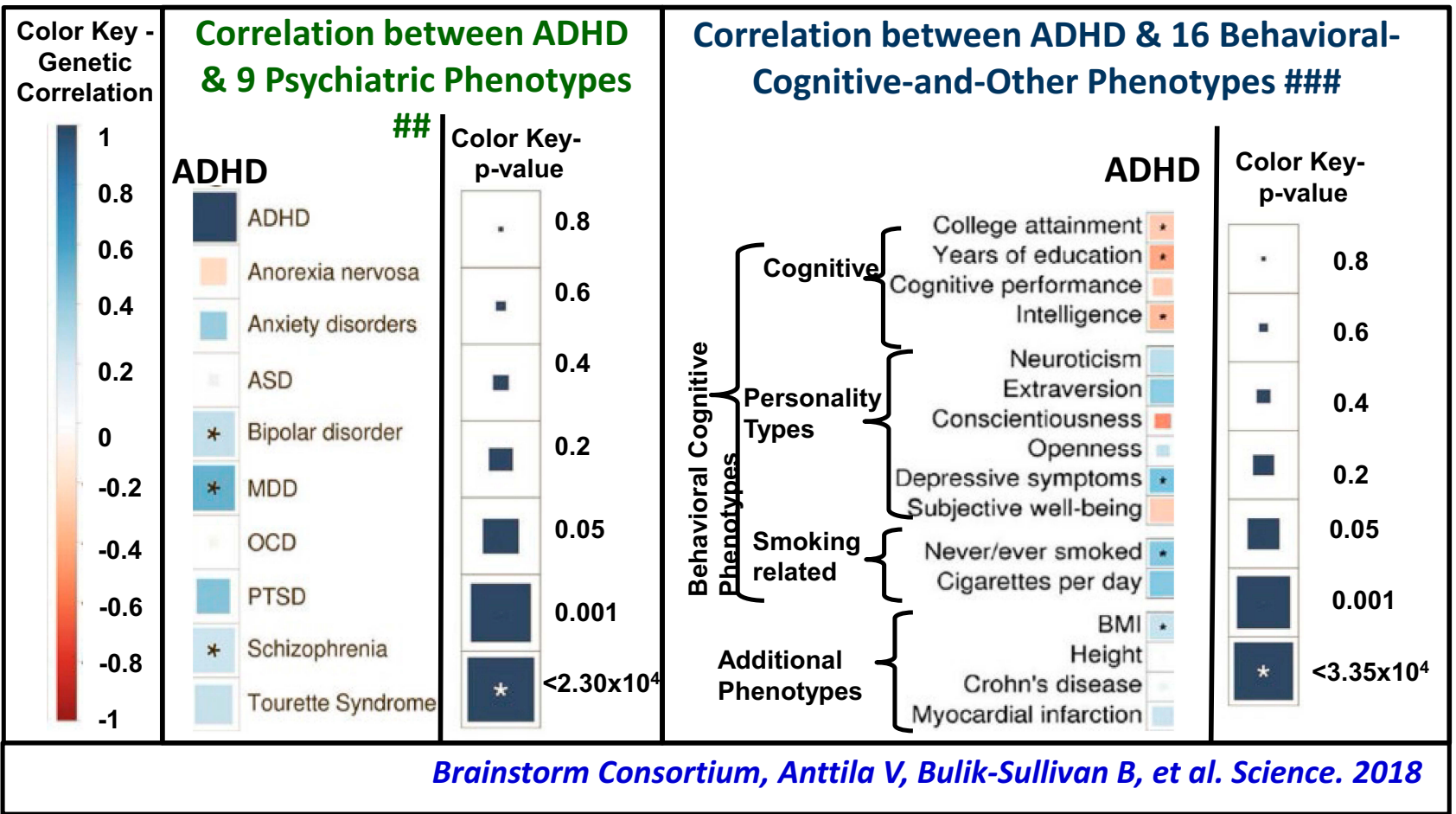

Attention Deficit Hyperactivity Disorder (ADHD), Autism Spectrum Disorder (ASD), Major Depressive Disorder (MDD), Anxiety disorders (generalized anxiety disorder, panic disorder, social phobia, agoraphobia, and specific phobias), Obsessive-Compulsive Disorder (OCD), Post-Traumatic Stress Disorder (PTSD) and Body Mass Index (BMI)

\#\# Data from 1,58,028 patients and 3,65,993 control participants totaling 5,24,021 participants \#\#\# Data from 11,24,048 participants

Figure 3 Correlation illustrating the shared genetics of adhd with selected psychiatric co-morbidities and behavioral-cognitive phenotypes. 
of 1,191,588 individuals). ${ }^{46}$ Results indicated that while neurological disorders appeared distinct from each other in terms of genetic risk, psychiatric disorders showed a high degree of genetic correlation with each other. Presented in Figure 3 is the correlation between ADHD and the other psychiatric disorders and the correlation between ADHD and the behavioral-cognitive phenotypes. This shared genetic etiology highlights the need to re-define both clinical and diagnostic boundaries to prevent diagnostic misclassification. Further, endophenotyping strategies need to ensure they reflect phenotypic heterogeneity that correlates with genetic correlations where psychiatric disorders are concerned.

\section{Neurobiological Studies on ADHD}

Deficits in working memory, cognitive flexibility, attention and inhibition are seen in ADHD. ${ }^{48-50}$ Both magnetic resonance imaging (MRI) and fMRI had highlighted the role of

(a) The frontoparietal, dorsal frontostriatal composed of the dorsolateral prefrontal cortex (PFC), dorsal striatum (DS), and the thalamus: attention and attention orientation),

(b) mesocorticolimbic circuits composed of the orbitofrontal cortex (OFC), ventral striatum and nucleus accumbens (NAcc), ventral tegmental area (VTA), and anterior hippocampus: reward and emotional processes, ie, motivation, frustration tolerance, and reward anticipation and

(c) the default mode network (DMN) that includes the medial prefrontal cortex (mPFC), posterior cingulate cortex (PCC), and lateral parietal cortex (LPC) and the cognitive control networks $(\mathrm{CCN})$ that includes the dorsolateral prefrontal cortex (DLPFC), anterior insular cortex (AIC), and supramarginal gyrus (SMG) in ADHD.

Studies on whole-brain structural MRI showed volumetric reductions in the basal ganglia in children with this reduction attenuating by adulthood. ${ }^{51-53}$ These findings help establish ADHD as a disorder that involved delayed neurobiological development. Another finding that supported this view was a longitudinal study of 223 children with ADHD with 223 healthy controls which demonstrated that ADHD children were $2-5$ years behind in achieving similar cortical thickness as healthy controls. ${ }^{54-56}$
Studies on neural connectivity in ADHD using diffusion MRI (dMRI) showed decreased fractional anisotropy (anterior corona radiata, internal capsule, and forceps minor and reduced orbitofrontal white matter organisation (mesocorticolimbic circuits)). ${ }^{57-59}$ Resting-state functional connectivity showed reduced connectivity within the DMN and task-based functional connectivity revealed increased activity for rest or introspective thought/tasks; while in controls DMN deactivation occurred as they transitioned to extrospective tasks a reduction in deactivation was seen in ADHD, which is possibly the cause of lapses or errors in goal-directed behavior. ${ }^{60-64}$ In terms of inhibitory control, a study of 287 individuals with ADHD and 320 healthy controls found that those with ADHD exhibit reduced activation in frontostriatal regions including the right inferior frontal cortex, striatum, and supplemental motor cortex during tasks requiring response inhibition. ${ }^{64-66}$

Functional MRI and diffusion tensor imaging studies have revealed impairments in prefrontal-striatal networks (inattention) and frontal-limbic networks (hyperactivity), over-activation of DMN-activation of fronto-striatal and fronto-parietal circuits, other frontal brain region and systems involved in executive function and attention to be implicated in ADHD. ${ }^{66-72}$ In terms of neurotransmitters, delayed maturation of certain dopaminergic neural pathways in children and adolescents with ADHD, lower levels of available dopamine receptor and transporter molecules in adults with ADHD and polymorphisms in the serotonin transporter gene (associated with differential response to ADHD treatment) and deficiencies in glutamate signaling characterize the disorder. ${ }^{73-77}$

\section{Electrophysiology and ADHD}

Figure 1 illustrates the facility with which EEG frequency analysis and ERP studies can be carried out using EEG machines like the NeuralScan by Medeia. Presented below are EEG-based studies on key aspects of ADHD.

Presented in Tables 1 and 2 is a summary of the approach followed in a recent review of EEG-based studies between 2000 and 2017 that examined ADHD-specific cognitive aspects (allocation of attentional resources, performance monitoring, and processing). ${ }^{78}$ Findings of the review were that in ADHD, in aspects of attention: orienting to cues, signaling response preparation, monitoring of conflict, rewarding feedback, and diminished inhibitory control were seen in young adulthood. The review also highlighted the need for studies between 16 and 26 age-group on ADHD. 
Table I Analytic Approach Followed to Review EEG-Based Cognitive Studies on ADHD from 2000 to 2017

\begin{tabular}{|c|c|c|}
\hline \multicolumn{2}{|c|}{ Analytical Approach } & \multirow{2}{*}{$\begin{array}{l}\text { Prominent Components \& Proposed Functional Significance } \\
\text { P50:sensory gating, NI (NI00): Sensory processing of unexpected (auditory) stimulus, } \\
\text { PI (PI00): Sensory processing of stimulus in the contralateral visual field, NI70: Structural encoding of faces, Early } \\
\text { posterior negativity (EPN): Selective visual attention toward emotional stimuli, Mismatch negativity (MMN): Detection } \\
\text { of infrequent and odd deviant stimulus in a repetitive sequence of auditory or visual stimuli }\end{array}$} \\
\hline ERP's & $\begin{array}{l}\text { Sensory } \\
\text { processing }\end{array}$ & \\
\hline & $\begin{array}{l}\text { Stimulus } \\
\text { evaluation }\end{array}$ & $\begin{array}{l}\text { N2: Detection of mismatch and/or inhibition of competing response, N250: Storage of face representation in long-term } \\
\text { memory, P2: Sensitivity to various stimulus features, P3a (novelty P3): Novelty processing and involuntary orienting of } \\
\text { attention, P3b (classic P3): Attentional engagement and stimulus evaluation/decision-making, N3 (slow wave or late } \\
\text { posterior negativity (LPN)), Enhanced attention to stimulus, particularly the nonautomatic, controlled part of the stimulus } \\
\text { processing, Negative-going wave over centropariental electrodes peaking at } 250-500 \text { ms poststimulus }\end{array}$ \\
\hline & $\begin{array}{l}\text { Response } \\
\text { preparation }\end{array}$ & $\begin{array}{l}\text { CNV Negative-going wave rising around } 260-470 \text { ms after a warning stimulus: Response and motor preparation to } \\
\text { upcoming stimulus, Lateralised readiness potential (LRP) Negative-going wave over motor cortices contralateral to the } \\
\text { responding hands: Motor preparation before action execution, Late positive potential (LPP): Salience of emotional stimuli }\end{array}$ \\
\hline & Error detection & $\begin{array}{l}\text { Error-related negativity (ERN) Negative-going wave rising 50-100 ms following erroneous response execution over } \\
\text { frontocentral electrodes: Unconscious error processing } \\
\text { Error-related positivity (PE) Positive-going wave over centro-parietal electrodes peaking around } 200-500 \text { ms post- } \\
\text { error, after the occurrence of ERN: Conscious error processing }\end{array}$ \\
\hline \multicolumn{2}{|c|}{ Quantitative EEG (qEEG) } & $\begin{array}{l}\text { Very-low frequency (VLF, 0.02-0.2 Hz): Default-mode network, Delta: Attention and inhibition, Theta: Cognitive } \\
\text { control, learning and memory, Alpha (8-12 Hz, over occipital cortex): Alertness, attention and inhibition, Mu rhythms } \\
\text { (8-13 Hz, over sensorimotor cortex): Action execution and observation of others' actions, Beta: Sensorimotor } \\
\text { processing and sensory gating, Gamma:Sensory binding } \\
\text { Evoked power \& Induced power: Dynamic changes in power of a given frequency band over time, Event-related phase- } \\
\text { locking OR inter-trial coherence (ITC), Consistency of timing of ERPs across trials (eg, neural variability), Coherence \& } \\
\text { Cross-frequency coupling: Brain's regional connectivity and interregional interaction }\end{array}$ \\
\hline
\end{tabular}

With ADHD being a delay in neural development more studies that cover childhood and young adulthood (till 25 years) are warranted. The review also highlighted the need for genetically informed studies (family studies and twin studies), studies across lifespan in executive functions and/ or decision-making processes, cross-border disorder diseases comparisons, whether ADHD was classified based on self-, parent- or teacher-reporting, neuroimaging and studies on remission and persistence of ADHD.

Another key aspect brought out by this review is ERPs subtypes exist based on the paradigm used to elicit them with the odd ball paradigm and its variations being used to study attention and ADHD. Paradigms used include;

- Stimuli (visual vs. auditory) cued continuous performance tasks (CPT), such as cue orienting (cue-trials), response execution (go-trials), response inhibition (no-go trials), trial conditions with inhibitory versus response demands.

- Performance monitoring (various facets of monitoring within the same task) including; conflict (errors and feedback), context monitoring (e.g., social vs. non-social),
- Face processing tasks (covering a range of positive and negative emotions), emotional conditions.

- Other paradigms used to evaluate cognitive ability include colour vision, orientation, brightness, pitch, motion, cross-modality integration, etc.

Such psychological, functional, and behavioral studies keeping in mind the structural, pathophysiological and environmental aspects of ADHD will certainly go a long way in clarifying the symptom and heritability sharing between ADHD, its comorbidities and cross-border disorders, aid in its endophenotyping and in identification of a diagnostic marker. ${ }^{79-81}$

\section{ADHD, Attention, Cognitive Performance, Default Mode Network (DMN) Deactivation}

The default mode network (DMN) which includes the medial prefrontal cortex (mPFC), posterior cingulate cortex (PCC)/ precuneus and medial, lateral and inferior parietal cortex medial prefrontal cortex (mPFC), posterior cingulate cortex (PCC)/precuneus and medial, lateral and inferior parietal 
Table 2 Neurocognitive Domains and the ERP Components Elicited via Appropriate Paradigms in EEG-Based Cognitive Studies on ADHD from 2000-2017

\begin{tabular}{|c|c|c|c|c|}
\hline $\begin{array}{l}\text { Neurocognitive } \\
\text { Domain }\end{array}$ & $\begin{array}{l}\text { Subprocesses } \\
\text { Investigated }\end{array}$ & EEG/ERP Components & Paradigms Used to Elicit ERPs & ADHD \\
\hline \multirow[t]{5}{*}{ Attention Processing } & Cue processing & $\begin{array}{l}\text { P50, PI, NI, P2, N2, P3a, P3b, TF-PCA of P3b, } \\
\text { LRP, CNV, VLF, delta, theta, alpha, beta, gamma }\end{array}$ & $\begin{array}{l}\text { Visual oddball, Auditory oddball \& go/no- } \\
\text { go, Fast task,Cued CPT } \\
\text { Eriksen flanker task, Two choice reaction }\end{array}$ & \\
\hline & Response preparation & CNV & Auditory oddball \& go/no-go & \\
\hline & Novelty processing & & & \\
\hline & Sustained attention & VLF & Cued CPT & \\
\hline & Perceptual binding & & & \\
\hline Inhibition Control & & PI, NI, P2, N2, P3b, LRP & Stop-signal Go/no-go & \\
\hline \multirow[t]{3}{*}{$\begin{array}{l}\text { Performance } \\
\text { Monitoring }\end{array}$} & Conflict monitoring & $\begin{array}{l}\text { N2, ERN, Pe, CNV, LPP, ITC, theta, early } \\
\text { positivity, }\end{array}$ & $\begin{array}{l}\text { Flankers task, Go/no-go, Incentive delay } \\
\text { task }\end{array}$ & \\
\hline & Error processing & ERN, Pe & Go/no-go & $*$ \\
\hline & Predictions & & & \\
\hline Face Processing & Structural encoding & $\mathrm{NI70}, \mathrm{PI}$ & Visual oddball with faces & \\
\hline \multirow[t]{3}{*}{ Sensory Processing } & Visual processing & PI, theta, alpha & $\begin{array}{l}\text { cVEP, Light flash paradigm Tone } \\
\text { processing during film. Brightness } \\
\text { detection task }\end{array}$ & $*$ \\
\hline & Auditory processing & NI, theta, alpha & Tone processing during film & $*$ \\
\hline & Context modulation & & & \\
\hline \multirow[t]{3}{*}{$\begin{array}{l}\text { Memory and } \\
\text { Language }\end{array}$} & Working memory & Alpha; P3b & $\begin{array}{l}\text { Delayed match-to-sample task Modified } \\
\text { I-back task }\end{array}$ & \\
\hline & Semantic processing & & & \\
\hline & Speech processing & & & \\
\hline
\end{tabular}

Note: EEG and ERP components where ADHD-autism spectrum disorder (ASD) shows an overlap. Boxes shaded grey indicates studies where the ERPs reflective of cogitative status in ADHD were elicited using appropriate paradigms. Blank cells indicate areas on EEG aspects of ADHD not yet studied. Note: Adapted from Lau-Zhu A, Fritz A, McLoughlin G. Overlaps and distinctions between attention deficit/hyperactivity disorder and autism spectrum disorder in young adulthood: Systematic review and guiding framework for EEG-imaging research. Neurosci Biobehav Rev. 2019;96:93-II5. Creative Commons license and disclaimer. ${ }^{78}$ Available from: http://creativecommons. org/licenses/by/4.0/legalcode"http://creativecommons.org/licenses/by/4.0/legalcode

cortex is active when the brain is at rest and deactivates with the onset of goal-directed tasks. ${ }^{82-90}$ Further, the DNM is comprised of both task-positive (extrospective attention) and task-negative (introspective attention) components with attenuation being directly correlated to the degree of complexity and cognitive challenge a task presents. ${ }^{82-90} \mathrm{DMN}$ oscillations are very low frequency (VLF) oscillations with individuals with ADHD exhibiting reduced DMN deactivation when transitioning from rest to a specific task, ie, increased reaction time variability (RTV). ${ }^{91-93}$ In a study on adults with low and high levels of ADHD Broyd et al compared EEG at rest and during a task that demanded attention. ${ }^{94}$ While both groups exhibited equivalent attention and performance via sLORETA it was found that both groups showed atypical deactivation, ie, the DMN regions deactivated differed. Attention-induced DMN deactivation occurred in the medial prefrontal regions (mPFC) in those with low-level ADHD while in those with high ADHD the temporal regions were deactivated.

\section{Inhibitory Control}

A study on inhibition control and ADHD highlighted deficits in the 'inhibition of interferences' and "action inhibition" via "Simon Tasks" and "Go/Nogo tasks". 
Findings revealed that inhibitory control operates on a hierarchical "first come, first serve" basis which is not integrated in ADHD. The defect was attributed to dysfunctions at the response selection level and fronto-parietal cortices. The clinical benefit of this finding it that it indicated that ADHD children required to be given simple step-wise instruction arranged in priority rather than complex situations requiring "if-then" decisions. Findings are also suggestive that behavioural, pharmacological and neurofeedback might help in this area. ${ }^{95}$

\section{Cognitive and Neurophysiological Markers of ADHD Persistence and Remission}

Childhood ADHD tends to persist into adulthood. ${ }^{96-98}$ In a six-year follow-up study of 279 individuals, 169 were controls, all with IQ>70; 23 (21\%) were remitters and the remaining were individuals in whom ADHD persisted among 110 individuals with childhood ADHD. ${ }^{99}$ Tests administered included; i) diagnostic (Diagnostic Interview for ADHD in adults, DIVA, Barkley Functional Impairment Scale, BFIS, ii) IQ (Wechsler Abbreviated Scale of Intelligence, WASI-III and digit span subtest for adults and children) and iii) activity level (Actigraphy). ${ }^{100-107}$ Neurophysiological tests using the i) the fast task, ii)Go/NoGo (GNG) task, and iii) cued flanker continuous performance task (CPT-OX) paradigms to elicit and measure EEG-based RTV, CNV, cue-P3, nogo-P3, commission error (CE) and omission error (OE) as well as delta, theta, alpha and beta power following Fast Fourier Transform (FFT) to evaluate attentional and inhibitory processes. ${ }^{102,108-113}$

The study was able to identify key markers of i) remission: preparation-vigilance measures (CNV, delta activity, RTV and OE) ii) moderator/s: IQ and iii) cognitive factors that did not influence the outcome of remission or persistence: executive control measures of inhibition or working memory (nogo-P3, CE and digit span backwards, DSB). ${ }^{21}$ Among the findings, preparation-vigilance processes have enormous clinical impact and potential in designing nonpharmacological interventions (cognitive training and neurofeedback) for individuals with ADHD. ${ }^{21}$ In terms of replication of results, this lack of association of executive control measures with ADHD remission was seen in some studies while in others no similar association was seen. ${ }^{114-121}$

Studies carried out to further examine factors influencing ADHD remission by Cheung et al, Michelini et al and James et al used the Fast Task with incentive paradigm and measured hypoarousal via skin conductance level
(SCL). ${ }^{122-124}$ ADHD remitters were similar to controls in baseline allocation (P3) and fast-incentive CNV amplitude both of which were found to be malleable components under fast task conditions. However, ADHD remitters differed to controls and were similar to ADHD persisters in terms of baseline peripheral arousal (SCL) which was also found to be modifiable under fast-task conditions. Thus, baseline SCL levels could prove as an enduring marker both in ADHD remitters and persistors. Here too treatment with MPH is found to improve both ADHD symptoms and peripheral arousal. ${ }^{125-127}$

Cheung et al, Du Reitz et al and Michelini et al worked on other aspects pertinent to diagnosis of ADHD persistence and remittance studies. ${ }^{123,128,129} \mathrm{Du}$ Rietz et al examined cognitive-neurophysiological and movement correlates of ADHD diagnosis of persistors and remitters based on parent/teacher reporting (common practice for childhood ADHD diagnosis) versus self-reported (common practice for adult ADHD diagnosis) among the same study population (6-year follow-up study). ${ }^{123,128}$ By DSM-V, ADHD persisters were $47 \%$ for selfreporting and $79 \%$ for parent-reporting. A key finding of the study was that self-report of ADHD persistence and remission did not correlate with neurophysiological and movement results obtained. The implications for follow-up studies of childhood ADHD are that both self-reported and parent/teacher reporting might need to be obtained. ${ }^{128}$

Michelini et al examined cognitive-performance measures and ERP's involved in conflict monitoring: N2 and error processing: error-related negativity, ERN, and positivity, Pe, from an arrow flanker task with low-conflict and high-conflict conditions. N2 is a frontocentral negative deflection obtained at $200-400 \mathrm{~ms}$ following a high conflict/incongruent stimulus (two competing responses and evaluation) when a correct response is made. ${ }^{129-131}$ If the subject makes an error, the ERN is recorded (frontocentral response-locked negative deflection at $0-150 \mathrm{~ms}$ ) followed by the Pe (centroparietal positive enhancement at 200-400 ms after response), ie, the ERN reflects unconscious response-monitoring system following a mistake while Pe represents conscious error processing to adjust response strategy. ${ }^{132-135}$ While N2 (for flanker task) showed no difference between persisters and remitters, enhancement of Pe (for Go/NoGo tasks) and ERN (for performancemonitoring tasks) was seen both in this study and has been reported in ADHD remitters. ${ }^{130,136-141}$ The findings of this study also illustrated the malleability of Pe and ERN and 
in turn the possibility of nonpharmacological interventions via Neurofeedback and behavioral training. ${ }^{129}$

\section{Reaction Time (RT), Reaction Time Variability (RTV), Malleability of RTV and Response Speed - ERP}

The EEG's and ERP's temporal precision was used by Cheung et al to study the relationship between cognitive performance via RTV both a heritable and malleable trait and response speed. ${ }^{122}$ The group examined P3 amplitudes (attention allocation) and contingent negative variation (CNV) a marker of preparation in 174 controls and 93 individuals with ADHD at baseline and following fast-incentive conditions of a four-choice reaction time task. P3 amplitudes were attenuated in ADHD individuals and RTV increased, with both ERP components proving malleable to fast-paced reward conditions. Twin studies have highlighted both heritability and the relationship between theta oscillations, RTV and ADHD. ${ }^{142}$ The CNV, reflecting cognitive anticipation and motor preparation, has been shown to be another heritable trait reduced in ADHD, neuro-developmentally delayed based on topographical studies. ${ }^{108,109,143-147}$ A key aspect worth noting is that the $\mathrm{CNV}$ calculated as the mean amplitude at $\mathrm{Cz}$ or $\mathrm{Pz}$, in milliseconds, varies in site and interval depending both on the age group studied and the paradigm used to elicit it. ${ }^{144,146,147}$

Studies have demonstrated the possibility of normalization of P3 and CNV amplitudes in ADHD following stimulant medication and methylphenidate (MPH) respectively. ${ }^{148-151}$ Studies using go/no-go tasks in combination with either neurofeedback or rewards/incentives have also shown them to be malleable to non-pharmacological techniques. ${ }^{152-157}$ One aspect to be kept in mind when considering comparison and efficacy studies is that while these interventions did help normalize response speeds in ADHD individuals, the use of rewards/incentives further also increases $\mathrm{CNV}$ amplitudes and reduces RTV/response times in healthy adults. ${ }^{158}$ Further as the mode of action of MPH which normalize CNV amplitudes is via the catecholaminergic pathway; the converse also applies, ie, CNV could serve as a catecholaminergic system marker. ${ }^{108,158}$ Cheung et al also looked at the relationship between P3, CNV, RTV and intellectual quotient (IQ) between controls and individuals with ADHD. While IQ exhibited a negative association with $\mathrm{P} 3$ amplitude such an association was absent among ADHD individuals. ${ }^{122,159}$
Reaction time variability (RTV) another candidate neurocognitive marker of ADHD refers to the degree of intraindividual variation in responding to a target stimulus, and increased reaction time variability on attention tasks has been commonly reported in ADHD youths. ${ }^{65,160,161}$ Frontal lobe damage increases RTV, while individual differences in RTV predict inhibitory success, subjects with increased RTV show greater activation during response inhibition tasks. ${ }^{162,163}$

A recent study ( $\mathrm{n}=1538$ youths) examined the relationship between ADHD symptoms, maps of dopaminergic gene expression (DRD1 and DRD2 gene), brain structure (ventromedial prefrontal cortex, vmPFC), and reaction time variability - an index of lapses in attention. It also tested for associations between brain structural correlates of ADHD symptomatology and maps of dopaminergic gene expression. Parent ratings, adolescent self-reports, and reaction time variability were negatively associated with gray matter volume (GMV), while DRD1 and DRD2 gene expression were associated with brain structural correlates of ADHD symptoms. Increased RTV on tasks of vigilant attention is common when comparing children with ADHD versus typically developing controls. ${ }^{65,161}$ The hypothesis is that increased RTV is linked to default mode network (DMN) activity typically attenuated during goal-directed tasks, can persist into periods of task-related processing and, as a result, compete with task-specific neural processing, eg, like working memory tasks. ${ }^{63}$ The vmPFC is a primary hub in the brain's DMN - a network posited to play a central role in mind-wandering and task-unrelated thought. Although speculative, it is possible that the volumetric reductions in the vmPFC may be linked to DMN dysfunction.

ADHD is characterized by greater intra-individual RTV during cognitive tasks. One commonality among these various populations with increased RTV are problems with attention, although there seems to be considerable variability in the types of attentional difficulties across populations (such as: selective, sustained and divided attention, and combinations of these). ${ }^{164-167}$ Studies on RTV and ADHD subtypes show poor correlation, RTV and reduced white matter volume show high correlation and RTV has been shown to improve with both stimulant medication and cognitive training. ${ }^{168-186}$

\section{Theta Beta Wave Power (TBR) and ADHD}

EEG studies on frequency analysis revealed an increase in theta wave power and/or decrease of beta wave power 
(TBR) in frontal areas, or a decrease in sensorimotor rhythm (SMR) power in the central area. ${ }^{187-210}$ Theta and TBR studies between 1930 and 1970 led to TBR to being a candidate diagnostic marker both in children and adults. However, TBRs variability with age, ADHD subtypes, its $63 \%$ sensitivity and $58 \%$ specificity when compared with clinical diagnosis of ADHD (gold standard) and its poor correlation with ADHD symptoms $(r=0.10$ for children and $r=-0.14$ for adults) have raised questions on its candidature. ${ }^{187-210}$ While some studies has revealed THBR to be a reliable marker of ADHD resulting in it being cleared by the FDA and the BlueCross others have had contrary results. ${ }^{211-213}$ No consistent theta or theta/ beta increases to diagnostically useful levels were found with ADHD. Thus, in order to prevent over diagnosis and misdiagnosis the TBR has been advocated only as an addon tool following clinical diagnosis. However, TBR has been very used successfully both as a tool to determine treatment efficacy and as a neurofeedback, NFB tool. ${ }^{187,191,208,209}$

The effects of an acute dose $(0.7 \mathrm{mg} / \mathrm{kg})$ of methylphenidate (MPH), known to improve home, school and cognitive task performance were evaluated via quantitative electroencephalography (QEEG) study following a oneweek washout period. ${ }^{214}$ The chief reason for use of QEEG was that it enabled both temporal and spatial study of attention using the continuous performance test (CPT) and test of variables of attention (T.O.V. A.). ${ }^{196,211,212,215,216}$ Results of the study ( $n=20$, 612years) were; for TOVA measures: omission error (oe, $\mathrm{p}<0.01$ ), commission errors (not-significant at $\mathrm{p}>0.05$ ), response time $(\mathrm{RT}, \mathrm{p}<0.05)$ and standard deviation $(\mathrm{p}<0.01)$ for $\mathrm{MPH}$-washout versus MPH-single-dose. MPH showed no brain wave frequency changes in the resting EEG state. However following CPT, increase in $\alpha$ (right and left frontal and occipital areas), $\beta$ activity (all areas except temporal brain region) and $\theta / \beta$ ratio (right frontal and parieto-occipital, and left temporal areas) was seen with decrease in $\theta$ (occipital and right temporoparietal areas), and $\delta$ activity (occipito-parietal areas). ${ }^{196}$

Another controlled, randomized, multigroup design, with pre-, post- and follow-up treatment phase study evaluated treatment efficacy of Neurofeedback, NFB $(n=19)$ versus pharmacological, $\mathrm{Rx}$ ( $\mathrm{n}=19$, MPH: $1 \mathrm{mg} / \mathrm{kilo} /$ day) therapy versus behavioral therapy, BT $(\mathrm{n}=19)$ and ADHD. ${ }^{177,191}$ NFB: 30 sessions of $\theta / \beta$ training at $4 /$ sessions week (30-s initial baseline $+24-\mathrm{min}$, ie, six 4-min runs, with a choice of 5 different screens like games, puzzles, etc., with rewards to ensure reinforcement). BT: 15 one-onone 50-min sessions of cognitive-behavioral therapy. Parents training: 10 weekly 90 -min sessions and teachers training: 5 group sessions, 90 min each. ${ }^{197-199}$ Evaluators were blinded to which child received which therapy. All three therapies showed similar TBR improvements $(p>0.05)$ indicating that they were equally effective (Hypothesis $(\mathrm{H})$, $\left.\mathrm{H}_{\mathrm{Rx}}=\mathrm{H}_{\mathrm{NFB}}=\mathrm{H}_{\mathrm{BT}}\right)$. While global attention $(p=0.002)$, auditory attention $(p=0.017)$ and visual attention $(p=0.028)$ were significant during treatment phase with the group on medication (Rx) showing the most improvement, the differences reached non-significance (NS) post-treatment. Classic resting-EEG patterns for children ADHD versus healthy developing controls indicate elevated $\theta$ and reduced $\alpha$ and $\beta$. A study to determine if these resting-EEG patterns were seen in adults evaluated 18 college students with ADHD and 17 controls. ${ }^{199}$ Adults with ADHD also exhibited the same neural abnormalities as children with ADHD with decrease in $\alpha$ and $\beta$, increase in $\theta$ and $\theta / \beta$ when relative power computation was carried out and this was more marked for eyes closed that eyes opened condition. vi.P3: In terms of P300 and ADHD, a recent meta-analysis observed that while P3b amplitude declines with age in non-ADHD controls, this decline was more marked in individuals with $\mathrm{ADHD}^{78,217,218}$ The neurobiological aspects linked with this finding are that cortical maturation in ADHD is delayed. ${ }^{219}$ The prefrontal cortex provides input signals for the ventral attention network, which is in turn linked with the P300b ERP component. ${ }^{220}$ Thus, if one wanted to examine the contributions of the prefrontal cortex to P3 generation it would be best to study prefrontal cortical maturation and P3 both in adolescence and young adulthood; ${ }^{221} \mathrm{P} 3$ indexes attention and memory processes, updating of mental representations stored in working memory based on novel incoming stimuli, attentional orienting either rapid, or passive attentional shifts to new/unexpected stimuli, or active attention shift due to a task. ${ }^{222-227}$ Auditory P3 amplitude increases across childhood-till 20 years whereas its latency decreases across lifespan. ${ }^{225} \mathrm{P} 3$ amplitude also shows variations in terms of electrode regions for which it is at peak across development. ${ }^{223,224}$ P300 variations have also been associated with, externalizing problems which are genetically mediated, social information processing style and high levels of aggression. P300 variations have also been associated with the distributed neural circuit including the lateral prefrontal cortex, both of which have shown impairments in externalizing disorders. ${ }^{228-236}$ P3 amplitudes have been also shown to 
vary depending on the paradigm used to elicit them. ${ }^{237-241}$ One study examined P3 amplitudes and topographical maps among the ADHD subtypes following the Go/NoGo task. ${ }^{141}$ The chief findings are (Figure 4) individuals with ADHD showed deficits in the anterior (frontal site) attentional system. ADHD-I and ADHD-H groups showed impairments for attention-demanding $\mathrm{Go} / \mathrm{NoGo}$ respond-to-target task, while the ADHD-H and ADHD-C exhibited slightly less impairment for inhibition-demanding Go/NoGo suppress-to-target task. ${ }^{141}$

\section{Sensori-Motor Rhythm (SMR) and ADHD} Several sleep disorders (sleep apnea and restless legs syndrome, idiopathic "sleep-onset insomnia" (SOI), also called "delayed sleep phase syndrome") are associated with ADHD. ${ }^{242,243}$ Sensori-motor rhythm (SMR) Neurofeedback studies revealed that this intervention normalized sleep and thus improved ADHD symptoms such as inattention and hyperactivity/impulsivity, demonstrated the role of sleep in cognition, reported that adult ADHD is characterized by a higher prevalence of "evening types", characterized by a delayed circadian phase. ${ }^{242-246}$ Arns et al demonstrated an association between high sunlight intensity and low ADHD prevalence in ADHD. ${ }^{242}$ Several studies have demonstrated that Sensori-motor rhythm neurofeedback (SMR) results in increased sleep spindle density during sleep, decreased sleep latency and increased total sleep time. ${ }^{247,248}$ Research has also demonstrated that melatonin results in an increased sleep spindle density and decreased sleep latency, suggesting overlap in the working mechanisms of SMR neurofeedback and melatonin. ${ }^{249}$ Sleep spindles are generated by the GABA-ergic thalamic reticular neurons and are synchronized through glutamatergic cortico-thalamic projections. ${ }^{250}$ SMR neurofeedback had its most specific effect on decreasing SOL. For TBR neurofeedback no association between clinical improvement and change in SOL or PSQI were found. Clinically, TBR and SMR neurofeedback had similar effects on symptom reduction in ADHD (inattention and hyperactivity/impulsivity); therefore, these results suggest differential effects and different working mechanisms for TBR and SMR neurofeedback in the treatment of ADHD.

\section{Sleep and ADHD}

A meta-analysis of sleep (polysomnographic and EEG) studies carried out over the last 15 years to examine macro- and microstructural alterations of sleep in ADHDS. Higher slow-wave activity (SWA) and theta oscillations were found to occur in ADHD during NonREM (NREM) and REM sleep. Higher theta activity is harmful to memory, performance and inhibitory control in ADHD. These changes in brainwave patterns could be due to delay in cortical maturation. Poor sleep quality in turn is known to affect cognitive function. ${ }^{187}$

\section{Resting State Studies and ADHD}

A meta-analysis on resting state condition (eyes open and closed) to examine the reliability of spectral analysis in studying psychiatric disorders identified 67 out 184 studies were ADHD. In the eyes closed condition for ADHDchildren power increases for delta and theta and decreases across alpha, beta and gamma and increase in absolute power for both delta and theta was seen. In the eyes open condition, an increase was dominant in both delta and theta for ADHD-children and in the delta band for ADHD-adults. Decreases in absolute power were dominant in the beta band for ADHD-children. Meta-analysis revealed that diametrically opposite results for absolute power vs relative power were only seen in the delta band for ADHD-children in the eyes closed condition. Relative power comparisons of controls to ADHD in children with eyes closed yielded a highest consistency score of 7.0 while the highest consistency scores for absolute power with eyes closed was 2.8 for ADHD in children. ${ }^{251}$

\section{Neurofeedback (NFB) and ADHD}

Meta-analysis of studies on neurofeedback where standard' neurofeedback protocols revealed three main factors impacted NFB efficacy: first, a intensity of treatment, but not treatment duration, second, using parent rating was better than teacher rating and third, using high-quality EEG equipment. ${ }^{188,189}$

\section{Stimulant Medication and ADHD}

A study was carried out to predict clinical gain and assess the risk of acute side effects of stimulant medication between without treatment (T1) and T2 on a single dose of stimulant medication groups using resting EEG (3-min eyes-closed, 3-min eyes-open), and $20 \mathrm{~min}$ cued visual GO/NOGO. EEG spectra, ERPs, omissions, commissions, RT, and RTV variability were computed. Excess theta in the ADHD group on treatment (T2) indicated positive treatment response and increased level of posterior alpha indicative of posterior hypoarousal were seen in nonresponders. $^{191}$ 
A Peak Amplitude and Latency of the P3a and P3b components associated with Go/NoGo targets

\begin{tabular}{|l|l|l|c|c|c|c|}
\hline \multicolumn{2}{|l|}{ Groups } & Control & ADHD-IA & ADHD-HI & ADHD-Combined \\
\hline \multirow{2}{*}{ Items Endorsed (Mean) } & Inattention & 3.06 & 15.18 & 6.43 & 14.87 \\
\cline { 2 - 7 } & Hyperactivity/Impulsivity & 1.75 & 4.62 & 11.25 & 15.87 \\
\hline \multirow{3}{*}{$\begin{array}{l}\text { Respond-To-Target } \\
\text { Task (Mean) }\end{array}$} & P3a & Amplitude $(\mu \mathrm{V})$ & 3.29 & 1.33 & 1.31 & 2 \\
\cline { 2 - 7 } & P3a & Latency $(\mathrm{ms})$ & 329 & 307 & 294 & 290 \\
\cline { 2 - 7 } & P3b & Amplitude $(\mu \mathrm{V})$ & 1.09 & 0.77 & 0.86 & 0.59 \\
\cline { 2 - 7 } & P3b & Latency $(\mathrm{ms})$ & 577 & 538 & 565 & 542 \\
\hline \multirow{3}{*}{$\begin{array}{l}\text { Suppress-To-Target } \\
\text { Task (Mean) }\end{array}$} & P3a & Amplitude $(\mu \mathrm{V})$ & 4.11 & 3.11 & 2.5 & 3.04 \\
\cline { 2 - 7 } & P3a & Latency $(\mathrm{ms})$ & 290 & 283 & 299 & 267 \\
\cline { 2 - 7 } & P3b & Amplitude $(\mu \mathrm{V})$ & 2.07 & 0.83 & 1.33 & 1.26 \\
\cline { 2 - 7 } & P3b & Latency $(\mathrm{ms})$ & 332 & 349 & 348 & 354 \\
\hline
\end{tabular}

\section{B Topographical Maps associated with Go/NoGo targets}

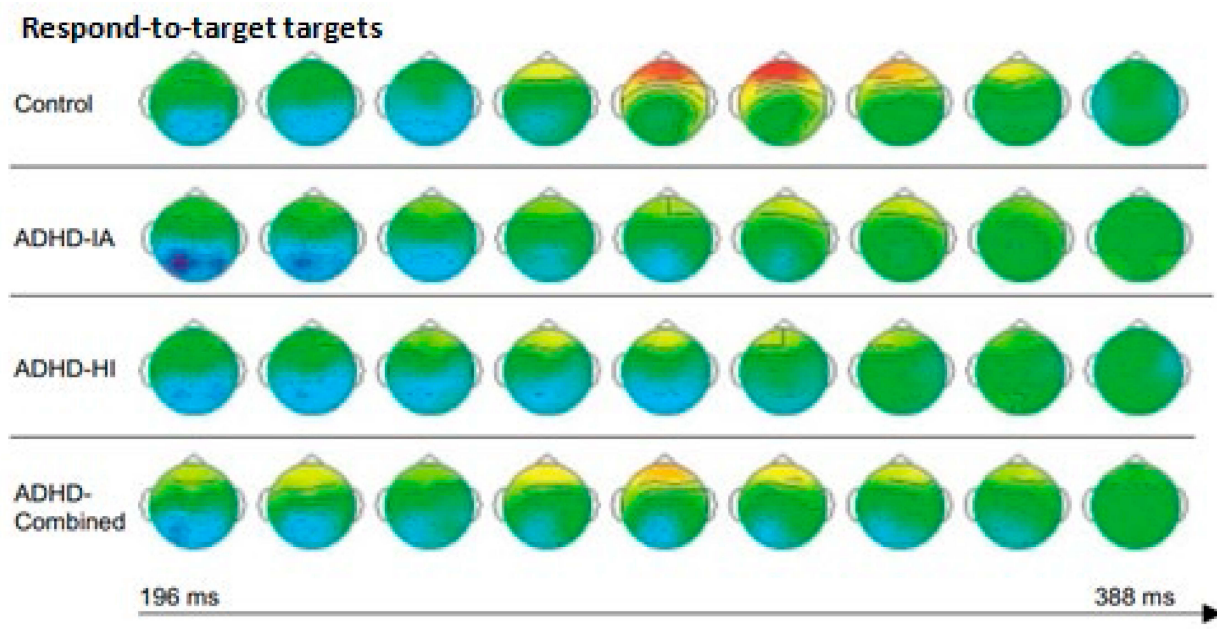

Suppress-to-target targets

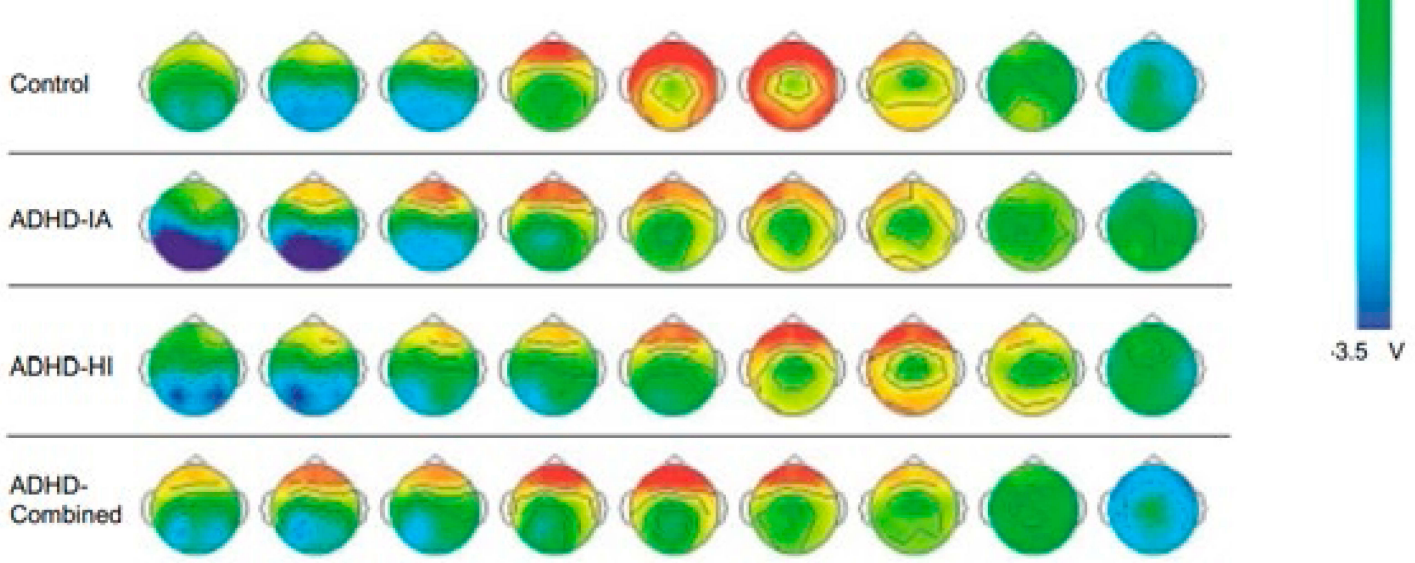

$196 \mathrm{~ms}$

$388 \mathrm{~ms}$

Figure 4 Attention among controls and individuals with self-reported ADHD captured via P3 following Go/NoGo Task Note: Adapted from Rodriguez PD, Baylis GC. Activation of brain attention systems in individuals with symptoms of ADHD. Behav Neurol. 2007;18(2):II5-30. Creative Commons license and disclaimer available from: http://creativecommons.org/licenses/by/4.0/legalcode"http://creativecommons.org/licenses/by/4.0/legalcode. ${ }^{14 I}$ 


\section{Pathagnomic/Endophenotyping Markers of ADHD .... Are We There Yet?}

With the shared heritability and symptom overlap seen in ADHD EEG-based endophenotyping holds promise in defining the etiology of ADHD. ${ }^{80,81,252,253} \mathrm{~A}$ recent study on heritability/genotyping of attention and inhibition processes in twins (67 male-only twin pairs) concordant and discordant for ADHD via ERPs and flanked CPT was carried out. ERPs were obtained for cue (P3, CNV or contingency negative variation), go (P3, N2) and nogo trials $(\mathrm{P} 3, \mathrm{~N} 2)$. No phenotypic associations were found between CPT-derived ERPs and ADHD. ${ }^{78}$ Do these findings imply that the quest for pathognomic/endophenotyping markers of ADHD is a futile one?

The present paper looked at EEG-based studies of ADHD on attention, cognitive performance, default mode network (DMN) deactivation, inhibitory control, cognitive and neurophysiological markers of ADHD persistence and remission, reaction time (RT), reaction time variability (RTV), malleability of RTV and response Speed - ERP, Theta Beta wave power (TBR), P3, sensori-motor rhythm (SMR), sleep, resting state studies, neurofeedback (NFB) and stimulant medication. Study findings illustrated distinct patterns in ADHD versus normal individuals. We also looked at key challenges in identifying potential pathognomic/endophenotyping markers of ADHD. Taken together the present work points at a framework, a stepwise systematic approach in the search for potential markers of ADHD (Figure 5):

Step-1: Defining the ADHD population and sub-groups if required,

Step-2: Symptom grouping (psychological phenotyping),

Step-3: Carrying out appropriate EEG-based studies (neurobiological phenotyping) for each symptom,

Step-4: Genotyping,

Step-5: Environmental risk factor grouping,

Step-6: Looking for patterns, association or causation depending on the study design.

\section{Questions This Step-Wise Approach Will Help Raise and Answer}

* Could one predict persisters/remitters and responders/ non-responders via neurobiological/EEG-based studies?

* Could overlapping symptoms among the cross-border co-morbid mental disorders extend to overlap in neurobiological and EEG patterns?

* If these psychiatric disorders share a common genetic risk then what causes a particular psychiatric disorder to dominate and clinically present? There are possibly distinct precipitating factors (genetic and non-genetic

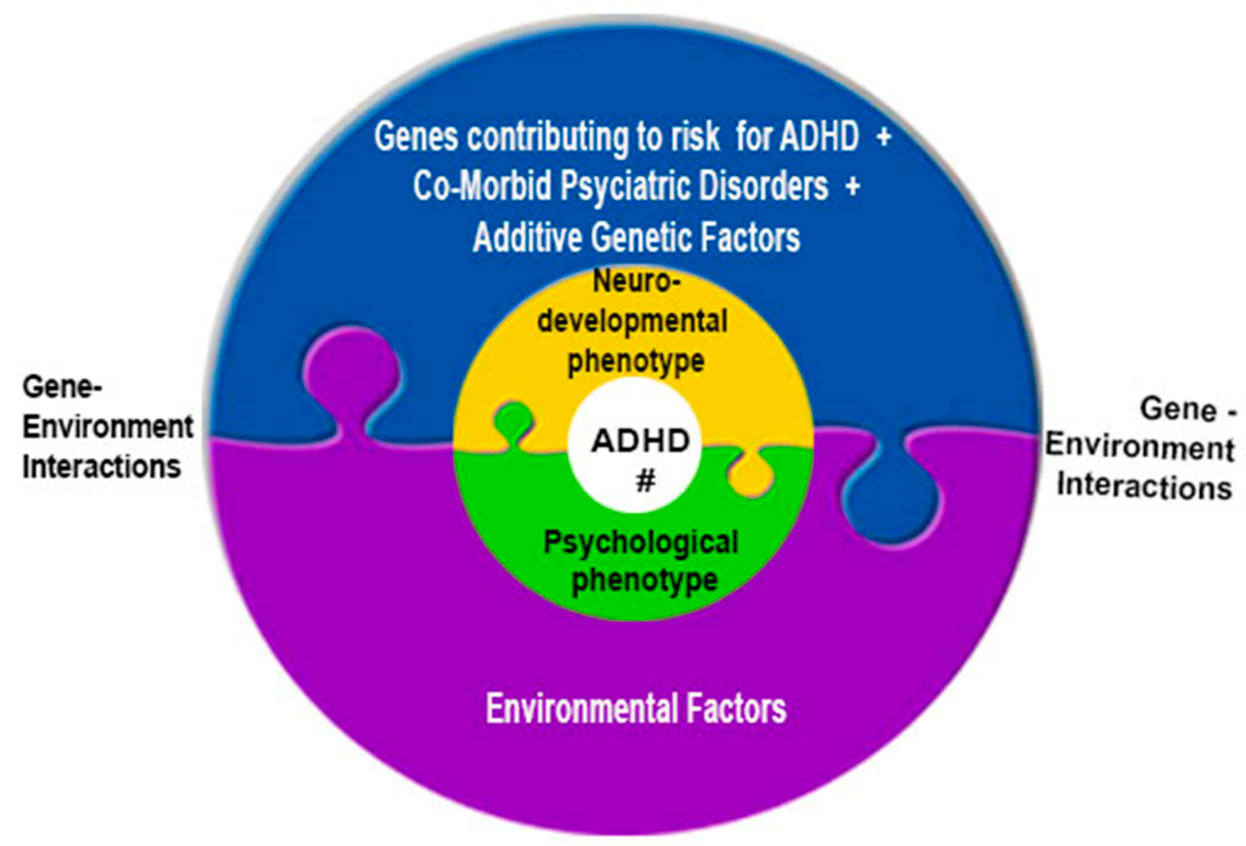

\# ADHD alone / ADHD + Co-Morbid Psychiatric Disorders

Figure 5 Diagrammatic illustration of the contributing factors to clinical phenotypic presentation of ADHD. 
perhaps environmental) yet unknown that eventually contribute to the clinical dominant outcome (Figure 5).

* Should shared genetic etiology highlight the need to re-define clinical and diagnostic boundaries to prevent diagnostic misclassification?

* Should endophenotyping strategies need to ensure they reflect phenotypic heterogeneity that correlates with genetic correlations where psychiatric disorders are concerned?

* Could another possible strategy be symptom-basedendophenotyping given the challenges in successful endophenotyping, diagnosing and treating psychiatric disorders with shared genetic heritability? For example, studying executive functioning in schizophrenia and ADHD or studying shared mechanism underlying cognitive biases in anorexia nervosa, obsessive-compulsive disorder (OCD) and schizophrenia. ${ }^{47}$

\section{Conclusion}

The quest for a pathognomonic marker for ADHD seems challenging when one considers the overlapping symptoms and shared heritability between its psychiatric co-morbidities and cross-border disorders. For the same reasons, endophenotyping has also proved challenging. With deficits in neurobiology via developmental delay being the core factor contributing to behavioural and clinical symptoms seen, it seems logical that neurobiological characterization of ADHD might hold the answer to a pathognomonic marker for ADHD. The interplay of heritable, developmental and environmental factors that cause ADHD to manifest as a fully developed condition while related disorders possessing the same risk factors do not remain to be fully explained (Figure 4). However, among the neurobiological tools available, EEG machines like NeuralScan by Medeia are a cost-effective tool providing an accurate temporal resolution which is vital in studying attention and inhibition and fast task responses in ADHD. Through these new state-of-the-art technologies it is now possible to achieve both temporal and spatial (sLORETA) resolution and power analysis (QEEG) which will enable and facilitate stepwise neurobiological characterization, diagnosis and management of ADHD. In addition, the EEG could help in identifying potential EEG-based pathognomic/endophenotyping markers of ADHD if a step-wise approach is followed. The framework for identifying potential EEG-based pathognomic/endophenotyping markers of ADHD is described in the present paper that takes into consideration the psychological and neurobiological phenotypes seen, the EEG-patterns observed, the genotype expressed and the environmental factors at play.

\section{Disclosure}

Dr Slav Danev is an employee of Medeia Inc, which makes the Neuralscan product.

The authors report no other conflicts of interest in this work.

\section{References}

1. American Psychiatric Association. Diagnostic and Statistical Manual of Mental Disorders. 1st ed. Washington, DC, USA: American Psychiatric Association; 1952.

2. American Psychiatric Association. Diagnostic and Statistical Manual of Mental Disorders. 2nd ed. Washington, DC, USA: American Psychiatric Association:; 1968.

3. American Psychiatric Association. Diagnostic and Statistical Manual of Mental Disorders. 3rd ed. Washington, DC, USA: American Psychiatric Association; 1980.

4. American Psychiatric Association. Diagnostic and Statistical Manual of Mental Disorders. 3rd rev ed. Washington, DC, USA: American Psychiatric Association; 1987.

5. American Psychiatric Association. Diagnostic and Statistical Manual of Mental Disorders. 4th ed. Arlington, VA, USA: American Psychiatric Association; 1994. 20. American Psychiatric Association. Diagnostic and Statistical Manual of Mental Disorders, 4th text rev. ed.; American Psychiatric Association: Arlington, VA, USA, 2000.

6. American Psychiatric Association. Diagnostic and Statistical Manual of Mental Disorders. 5th ed. Washington, DC, USA: American Psychiatric Association; 2013.

7. Kooij JJ, Huss M, Asherson P, et al. Distinguishing comorbidity and successful management of adult ADHD. J Atten Disord. 2012;16(5 Suppl):3S-19S. doi:10.1177/1087054711435361

8. Gloss D, Varma JK, Pringsheim T, Nuwer MR. Practice advisory: the utility of EEG theta/beta power ratio in ADHD diagnosis: report of the guideline development, dissemination, and implementation subcommittee of the American Academy of Neurology. Neurology. 2016;87(22):2375-2379.

9. Lenartowicz A, Loo SK. Use of EEG to diagnose ADHD. Curr Psychiatry Rep. 2014;16(11):498. doi:10.1007/s11920-014-04 98-0

10. McLoughlin G, Makeig S, Tsuang MT. In search of biomarkers in psychiatry: EEG-based measures of brain function. $\mathrm{Am} \mathrm{J} \mathrm{Med}$ Genet B Neuropsychiatr Genet. 2014;165:111-121. doi:10.1002/ ajmg.b. 32208

11. Markiewcz R. The use of EEG biofeedback/neurofeedback in psychiatric rehabilitation. Psychiatr Pol. 2017;51(6):1095-1106. doi:10.12740/PP/68919 Epub 2017 Dec 30.

12. Crichton A. An inquiry into the nature and origin of mental derangement: comprehending a concise system of the physiology and pathology of the human mind and a history of the passions and their effects. J Atten Disord. 1798;12:200-204. [Cadell T Jr, Davies W, London [Reprint: Crichton A (2008) An inquiry into the nature and origin of mental derangement. On attention and its diseases. doi: $10.1177 / 1087054708315137$

13. Palmer E, Finger S. An early description of ADHD (Inattentive Subtype): dr Alexander Crichton and 'Mental Restlessness' (1798) Child Psychol Psychiatry Rev. 2001;6:66-73.

14. Lange KW, Reichl S, Lange KM, Tucha L, Tucha O. The history of attention deficit hyperactivity disorder. Atten Defic Hyperact Disord. 2010;2(4):241-255. doi:10.1007/s12402-010-0045-8

15. Carlew AR, Zartman AL. DSM nosology changes in neuropsychological diagnoses through the years: a look at ADHD and mild neurocognitive disorder. Behav Sci (Basel). 2016;7(1):1. doi:10. 3390/bs7010001 
16. Barkley RA. Issues in the diagnosis of attention-deficit/hyperactivity disorder in children. Brain Dev. 2003;25:77-83. doi:10.1016/S0387-7604(02)00152-3

17. Barkley RA. Behavioral inhibition, sustained attention, and executive functions: constructing a unifying theory of ADHD. Psychol Bull. 1997;121:65-94. doi:10.1037/0033-2909.121.1.65

18. Barkley RA. Concentration deficit disorder (sluggish cognitive tempo). In: Attention Deficit Hyperactivity Disorder: A Handbook for Diagnosis and Treatment. New York, NY, USA: Guilford Press; 2015:267-313.

19. American Academy of Pediatrics. Clinical Practice Guideline: diagnosis and evaluation of the child with attention-deficit/hyperactivity disorder. Pediatrics. 2000;105:1158-1170. doi:10.1542/ peds.105.5.1158

20. Fayyad J, Sampson NA, Hwang I, et al. The descriptive epidemiology of DSM-IV adult ADHD in the World Health Organization World Mental Health Surveys. Atten Defic Hyperact Disord. 2017;9:47-65. doi:10.1007/s12402-016-0208-3

21. Faraone SV, Biederman J, Mick E. The age-dependent decline of attention deficit hyperactivity disorder: a meta-analysis of follow-up studies. Psychol Med. 2006;36:159-165.

22. Ebejer JL, Medland SE, van der Werf J, et al. Attention deficit hyperactivity disorder in Australian adults: prevalence, persistence, conduct problems and disadvantage. PLoS One. 2012;7: e47404. doi:10.1371/journal.pone.0047404

23. Torgersen T, Gjervan B, Rasmussen K. ADHD in adults: a study of clinical characteristics, impairment and comorbidity. Nord J Psychiatry. 2006;60(1):38-43. doi:10.1080/08039480500520665

24. Sobanski E, Brüggemann D, Alm B, et al. Psychiatric comorbidity and functional impairment in a clinically referred sample of adults with attention-deficit/hyperactivity disorder (ADHD). Eur Arch Psychiatry Clin Neurosci. 2007;257(7):371-377. doi:10.1007/s00 406-007-0712-8

25. Anker E, Bendiksen B, Heir T. Comorbid psychiatric disorders in a clinical sample of adults with ADHD, and associations with education, work and social characteristics: a cross-sectional study. BMJ Open. 2018;8(3):e019700. doi:10.1136/bmjopen-2017-01 9700

26. Russell G, Rodgers LR, Ukoumunne OC, Ford T. Prevalence of parent-reported ASD and ADHD in the UK: findings from the millennium cohort study. J Autism Dev Disord. 2014;44:31-40. doi:10.1007/s10803-013-1849-0

27. van der Meer JMJ, Oerlemans AM, van Steijn DJ, et al. Are autism spectrum disorder and attention-deficit/hyperactivity disorder different manifestations of one overarching disorder? Cognitive and symptom evidence from a clinical and population-based sample. J Am Acad Child Adolesc Psychiatry. 2012;51:1160-1172.e3. doi:10.1016/j.jaac.2012.08.024

28. Katzman MA, Bilkey TS, Chokka PR, Fallu A, Klassen LJ. Adult ADHD and comorbid disorders: clinical implications of a dimensional approach. BMC Psychiatry. 2017;17(1):302. doi:10.1186/s12888-017-1463-3

29. Klassen LJ, Katzman MA, Chokka P. Adult ADHD and its comorbidities, with a focus on bipolar disorder. J Affect Disord. 2010;124(1-2):1-8. doi:10.1016/j.jad.2009.06.036

30. McIntosh D, Kutcher S, Binder C, Levitt A, Fallu A, Rosenbluth M. Adult ADHD and comorbid depression: a consensus-derived diagnostic algorithm for ADHD. Neuropsychiatr Dis Treat. 2009;5:137-150. doi:10.2147/ndt.s4720

31. Canadian Attention Deficit Hyperactivity Disorder Resource Alliance (CADDRA): Canadian ADHD Practice Guidelines. $3^{\text {rd }}$ ed. Toronto ON: CADDRA; 2011

32. Deberdt W, Thome J, Lebrec J, et al. Prevalence of ADHD in nonpsychotic adult psychiatric care (ADPSYC): A multinational cross-sectional study in Europe. BMC Psychiatry. 2015;15:242. doi:10.1186/s12888-015-0624-5
33. Reale L, Bartoli B, Cartabia M, et al.; Lombardy ADHD Group. Comorbidity prevalence and treatment outcome in children and adolescents with ADHD. Eur Child Adolesc Psychiatry. 2017;26 (12):1443-1457. Epub 2017 May 19. doi:10.1007/s00787-0171005-z

34. Chen W, Zhou K, Sham P, et al. DSM-IV combined type ADHD shows familial association with sibling trait scores: a sampling strategy for QTL linkage. Am J Med Genet B Neuropsychiatr Genet. 2008;147B:1450-1460. doi:10.1002/ajmg.b.30672

35. Sherman D, Iacono W, McGue M. Attention deficit hyperactivity disorder dimensions: a twin study of inattention and impulsivity hyperactivity. $J$ Am Acad Child Adolesc Psychiatry. 1997;36:745-753. doi:10.1097/00004583-199706000-00010

36. Langner I, Garbe E, Banaschewski T, Mikolajczyk RT. Twin and sibling studies using health insurance data: the example of attention deficit/hyperactivity disorder (ADHD). PLoS One. 2013;8: e62177. doi:10.1371/journal.pone.0062177

37. Gizer IR, Ficks C, Waldman ID. Candidate gene studies of ADHD: a meta-analytic review. Hum Genet. 2009;126:51-90.

38. Bonvicini C, Faraone SV, Scassellati C. Attention-deficit hyperactivity disorder in adults: a systematic review and metaanalysis of genetic, pharmacogenetic and biochemical studies. Mol Psychiatry. 2016;21:1643. doi:10.1038/mp.2016.128

39. Faraone SV, Mick E. Molecular genetics of attention deficit hyperactivity disorder. Psychiatr Clin North Am. 2010;33 (1):159-180. doi:10.1016/j.psc.2009.12.004

40. Schachar R. Genetics of Attention Deficit Hyperactivity Disorder (ADHD): recent updates and future prospects. Curr Dev Disord Rep. 2014;1:41. doi:10.1007/s40474-013-0004-0

41. Lai CS, Gerrelli D, Monaco AP, Fisher SE, Copp AJ. FOXP2 expression during brain development coincides with adult sites of pathology in a severe speech and language disorder. Brain. 2003;126(Pt 11):2455-2462. doi:10.1093/brain/awg247

42. Demontis D, Walters RK, Martin J, et al. Discovery of the first genome-wide significant risk loci for ADHD. Submitted for Publication, bioRxiv. 2017;14558:1-43.

43. Valbonesi S, Magri C, Traversa M, et al. Copy number variants in attention-deficit hyperactive disorder: identification of the $15 \mathrm{q} 13$ deletion and its functional role. Psychiatr Genet. 2015;25:59-70. doi:10.1097/YPG.0000000000000056

44. Kollins SH, McClernon FJ, Fuemmeler BF. Association between smoking and attention-deficit/hyperactivity disorder symptoms in a population-based sample of young adults. Arch Gen Psychiatry. 2005;62:1142-1147. doi:10.1001/archpsyc.62.10.1142

45. Levin ED, Conners CK, Silva D, et al. Transdermal nicotine effects on attention. Psychopharmacol (Berl). 1998;140:135-141. doi:10. 1007/s002130050750

46. Anttila V, Bulik-Sullivan B, et al.; Brainstorm Consortium. Analysis of shared heritability in common disorders of the brain. Science. 2018;360(6395):eaap8757. doi:10.1126/science.aap8757.

47. Willcutt EG, Doyle AE, Nigg JT, Faraone SV, Pennington BF. Validity of the executive function theory of attention-deficit/ hyperactivity disorder: a meta-analytic review. Biol Psychiatry. 2005;57:1336-1346. doi:10.1016/j.biopsych.2005.02.006;pmid

48. Banaschewski T, Hollis C, Oosterlaan J, et al. Towards an understanding of unique and shared pathways in the psychopathophysiology of ADHD. Dev Sci. 2005;8(2):132-140. doi:10.1111/ j.1467-7687.2005.00400.x

49. Gallo EF, Posner J. Moving towards causality in attention-deficit hyperactivity disorder: overview of neural and genetic mechanisms. Lancet Psychiatry. 2016;3(6):555-567. doi:10.101 6/S2215-0366(16)00096-1

50. Shaw P, Eckstrand K, Sharp W, et al. Attention-deficit/hyperactivity disorder is characterized by a delay in cortical maturation. Proc Natl Acad Sci U S A. 2007;104:19649-19654. doi:10.1073/ pnas.0707741104 
51. Ellison-Wright I, Ellison-Wright Z, Bullmore E. Structural brain change in attention deficit hyperactivity disorder identified by meta-analysis. BMC Psychiatry. 2008;8:51. doi:10.1186/1471244X-8-51

52. Nakao T, Radua C, Rubia K, Mataix-Cols D. Gray matter volume abnormalities in ADHD: voxel-based meta-analysis exploring the effects of age and stimulant medication. Am $J$ Psychiatry. 2011;168:1154-1163. doi:10.1176/appi.ajp.2011.11020281

53. Frodl T, Skokauskas N. Meta-analysis of structural MRI studies in children and adults with attention deficit hyperactivity disorder indicates treatment effects. Acta Psychiatr Scand. 2012;125: 114-126. doi:10.1111/j.1600-0447.2011.01786.x

54. Almeida LG, Ricardo-Garcell J, Prado H, et al. Reduced right frontal cortical thickness in children, adolescents and adults with ADHD and its correlation to clinical variables: a cross-sectional study. J Psychiatr Res. 2010;44:1214-1223. doi:10.1016/j.jpsychires.2010.04.026

55. Montes LGA, Alcántara HP, García RBM, De La Torre LB, Acosta DÁ, Duarte MG. Brain cortical thickness in ADHD: age, sex, and clinical correlations. J Atten Disord. 2012;17: 641-654. doi:10.1177/1087054711434351

56. Rubia K. Neuro-anatomic evidence for the maturational delay hypothesis of ADHD. Proc Natl Acad Sci USA. 2007;104: 19663-19664. doi:10.1073/pnas.0710329105

57. van Ewijk H, Heslenfeld DJ, Zwiers MP, Buitelaar JK, Oosterlaan J. Diffusion tensor imaging in attention deficit/hyperactivity disorder: a systematic review and meta-analysis. Neurosci Biobehav Rev. 2012;36:1093-1106. doi:10.1016/j.neubiorev.2012. 01.003

58. Nagel BJ, Bathula D, Herting M, et al. Altered white matter microstructure in children with attention-deficit/hyperactivity disorder. J Am Acad Child Adolesc Psychiatry. 2011;50:28 3-292. doi:10.1016/j.jaac.2010.12.003

59. Cha J, Fekete T, Siciliano F, et al. Neural correlates of aggression in medication-naive children with ADHD: multivariate analysis of morphometry and tractography. Neuropsychopharmacology. 2015;40:1717-1725. doi:10.1038/npp.2015.18

60. Posner J, Park C, Wang Z. Connecting the dots: a review of resting connectivity MRI studies in attention-deficit/hyperactivity disorder. Neuropsychol Rev. 2014;24:3-15. doi:10.1007/s11065014-9251-z

61. Fair DA, Posner J, Nagel BJ, et al. Atypical default network connectivity in youth with attention-deficit/hyperactivity disorder. Biol Psychiatry. 2010;68:1084-1091. doi:10.1016/j. biopsych.2010.07.003

62. Castellanos FX, Margulies DS, Kelly C, et al. Cingulateprecuneus interactions: a new locus of dysfunction in adult attention-deficit/hyperactivity disorder. Biol Psychiatry. 2008;63: 332-337. doi:10.1016/j.biopsych.2007.06.025

63. Sonuga-Barke EJ, Castellanos FX. Spontaneous attentional fluctuations in impaired states and pathological conditions: a neurobiological hypothesis. Neurosci Biobehav Rev. 2007;31:977-986. doi:10.1016/j. neubiorev.2007.02.005

64. Peterson BS, Potenza MN, Wang Z, et al. An FMRI study of the effects of psychostimulants on default-mode processing during Stroop task performance in youths with ADHD. Am J Psychiatry. 2009;166:1286-1294. doi:10.1176/appi.ajp.2009.08050724

65. Hart H, Radua J, Nakao T, Mataix-Cols D, Rubia K. Meta-analysis of functional magnetic resonance imaging studies of inhibition and attention in attention-deficit/hyperactivity disorder: exploring task-specific, stimulant medication, and age effects. JAMA Psychiatry. 2013; 70:185-198. doi:10.1001/jamapsychiatry.2013.277

66. Cortese S, Kelly C, Chabernaud C, et al. Toward systems neuroscience of ADHD: a meta-analysis of 55 fMRI studies. $\mathrm{Am}$ J Psychiatry. 2012;169:1038-1055. doi:10.1176/appi.ajp.2012.11 101521
67. Makris N, Biederman J, Valera EM, et al. Cortical thinning of the attention and executive function networks in adults with attention-deficit/hyperactivity disorder. Cereb Cortex. 2007;17:13 64-1375. doi:10.1093/cercor/bhl047

68. Purper-Ouakil D, Ramoz N, Lepagnol-Bestel AM, et al. Neurobiology of attention deficit/hyperactivity disorder. Pediatr Res. 2011;69:69R-76R. doi:10.1203/PDR.0b013e318212b40f

69. Morein-Zamir S, Dodds C, van Hartevelt TJ, et al. Hypoactivation in right inferior frontal cortex is specifically associated with motor response inhibition in adult ADHD. Hum Brain Mapp. 2014;35:5141-5152. doi:10.1002/hbm.22539

70. Karch S, Voelker JM, Thalmeier T, et al. Deficits during voluntary selection in adult patients with ADHD: new insights from single-trial coupling of simultaneous EEG/fMRI. Front Psychiatry. 2014;5:41. doi:10.3389/fpsyt.2014.00041

71. Dickstein SG, Bannon K, Castellanos FX, et al. The neural correlates of attention deficit hyperactivity disorder: an ALE meta-analysis. J Child Psychol Psychiatry. 2006;47:1051-1062. doi:10.1111/j.1469-7610.2006.01671.x

72. Cubillo A, Halari R, Giampietro V, et al. Fronto-striatal underactivation during interference inhibition and attention allocation in grown up children with attention deficit/hyperactivity disorder and persistent symptoms. Psychiatry Res. 2011;193:17-27. doi:10.1016/j.pscychresns.2010.12.014

73. Volkow ND, Wang GJ, Newcorn J, et al. Depressed dopamine activity in caudate and preliminary evidence of limbic involvement in adults with attention-deficit/hyperactivity disorder. Arch Gen Psychiatry. 2007;64:932-940. doi:10.1001/archpsyc.64.8.932

74. Maltezos S, Horder J, Coghlan S, et al. Glutamate/glutamine and neuronal integrity in adults with ADHD: a proton MRS study. Transl Psychiatry. 2014;4:e373. doi:10.1038/tp.2014.11

75. Perlov E, Philipsen A, Hesslinger B, et al. Reduced cingulate glutamate/glutamine-to-creatine ratios in adult patients with attention deficit/hyperactivity disorder - a magnet resonance spectroscopy study. J Psychiatr Res. 2007;41:934-941. doi:10.1016/j. jpsychires.2006.12.007

76. Del Campo N, Fryer TD, Hong YT, et al. A positron emission tomography study of nigro-striatal dopaminergic mechanisms underlying attention: implications for ADHD and its treatment. Brain. 2013;136:3252-3270. doi:10.1093/brain/awt263

77. Tomasi D, Volkow ND. Functional connectivity of substantia nigra and ventral tegmental area: maturation during adolescence and effects of ADHD. Cereb Cortex. 2014;24:935-944. doi:10.10 93/cercor/bhs 382

78. Lau-Zhu A, Fritz A, McLoughlin G. Overlaps and distinctions between attention deficit/hyperactivity disorder and autism spectrum disorder in young adulthood: systematic review and guiding framework for EEG-imaging research. Neurosci Biobehav Rev. 2019;96:93-115. doi:10.1016/j.neubiorev.2018.10.009

79. Thapar A, Cooper M, Rutter M. Neurodevelopmental disorders. Lancet Psychiatry. 2017;4:339-346. doi:10.1016/S2215-0366(16) 30376-5

80. Beauchaine TP. The role of biomarkers and endophenotypes in prevention and treatment of psychopathological disorders. Biomark Med. 2009;3(1):1-3. doi:10.2217/17520363.3.1.1

81. Beauchaine TP, Constantino JN. Redefining the endophenotype concept to accommodate transdiagnostic vulnerabilities and etiological complexity. Biomark Med. 2017;11(9):769-780. doi:10.22 17/bmm-2017-0002

82. McKiernan KA, D’Angelo BR, Kaufman JN, Binder JR. Interrupting the 'stream of consciousness': an fMRI investigation. NeuroImage. 2006;29:1185-1191. doi:10.1016/j.neuroimage.2005.09.030

83. Uddin LQ, Kelly AMC, Biswal BB, Castellanos FX, Milham MP Functional connectivity of default mode network components: correlation, anticorrelation and causality. Hum Brain Mapp. 2009;30:625-637. doi:10.1002/hbm.20531 
84. Fox MD, Corbetta M, Snyder AZ, Vincent JL, Raichle ME. Spontaneous neuronal activity distinguishes human dorsal and ventral attention systems. Proc Natl Acad Sci $U S A$. 2006b;103:10046-10051. doi:10.1073/pnas.0604187103

85. Fox MD, Snyder AZ, Vincent JL, et al. The human brain is intrinsically organised into dynamic, anticorrelated functional networks. Proc Natl Acad Sci U S A. 2005;102:9673-9678. doi:10.1073/pnas.0504136102

86. Greicius MD, Krasnow B, Reiss AL, Menon V. Functional connectivity in the resting brain: a network analysis of the default mode hypothesis. Proc Natl Acad Sci U S A. 2003;100:253-258. doi:10.1073/pnas.0135058100

87. Raichle ME, MacLeod AM, Snyder AZ, et al. A default mode of brain function. Proc Natl Acad Sci US A. 2001;98:676-682. doi:10.1073/pnas.98.2.676

88. Damoiseaux JS, Rombouts SARB, Barkhof F, et al. Consistent resting-state networks across healthy subjects. Proc Natl Acad Sci US A. 2006;103:13848-13853. doi:10.1073/pnas.0601417103

89. Beckmann CF, DeLuca M, Devlin JT, Smith SM. Investigations into resting-state connectivity using independent component analysis. Philos Trans R Soc B. 2005;360. doi:10.1098/rstb.2005.1634

90. Corbetta M, Shulman GL. Control of goal-directed and stimulus-driven attention in the brain. Nat Rev Neurosci. 2002;3:215-229. doi:10.1038/nrn755

91. Buzsáki G, Draguhn A. Neuronal oscillations in cortical networks. Science. 2004;304:1926-1929. doi:10.1126/science.1099745

92. Weissman DH, Roberts KC, Visscher KM, Woldorff MG. The neural basis of momentary lapses in attention. Nat Neurosci. 2006;9:971-978. doi:10.1038/nn1727

93. Fassbender C, Zhang H, Buzy WM, et al. A lack of default network suppression is linked to increased distractibility in ADHD. Brain Res. 2009;1273:114-128. doi:10.1016/j.brainres.2009.02.070

94. Broyd SJ, Helps SK, Sonuga-Barke EJ. Attention-induced deactivations in very low frequency EEG oscillations: differential localisation according to ADHD symptom status. PLoS One. 2011;6(3):e17325. doi:10.1371/journal.pone.0017325

95. Chikara RK, Ko LW. Neural activities classification of human inhibitory control using hierarchical model. Sensors (Basel). 2019;19(17):E3791. doi:10.3390/s19173791

96. Faraone SV, Biederman J, Mick E. The age-dependent decline of attention deficit hyperactivity disorder: a meta-analysis of follow-up studies. Psychol Med. 2006;36:159-165.

97. Polanczyk G, de Lima MS, Horta BL, Biederman J, Rohde LA. The worldwide prevalence of ADHD: A systematic review and metaregression analysis. American Journal of Psychiatry. 2007;164:942-948. doi:10.1176/ajp.2007.164.6.942

98. Simon V, Czobor P, Balint S, Meszaros A, Bitter I. Prevalence and correlates of adult attention-deficit hyperactivity disorder: meta-analysis. Br J Psychiatry. 2009;194:204-211. doi:10.1192/ bjp.bp.107.048827

99. Cheung CHM, Rijsdijk F, McLoughlin G, et al. Cognitive and neurophysiological markers of ADHD persistence and remission. The British Journal of Psychiatry. J Ment Sci. 2016;208:548-555.

100. Wood AC, Rijsdijk F, Johnson KA, et al. The relationship between ADHD and key cognitive phenotypes is not mediated by shared familial effects with IQ. Psychol Med. 2011;41:861-871. doi:10. 1017/S003329171000108X

101. Cheung CH, Fazier-Wood AC, Asherson P, Rijsdijk F, Kuntsi J. Shared cognitive impairments and aetiology in ADHD symptoms and reading difficulties. PLoS One. 2014;9:e98590. doi:10.1371/ journal.pone.0098590

102. Wood AC, Asherson P, Rijsdijk F, Kuntsi J. Is overactivity a core feature in ADHD? Familial and receiver operating characteristic curve analysis of mechanically assessed activity level. J Am Acad Child Adolesc Psychiatry. 2009;48:1023-1030. doi:10.1097/CHI. ob013e3181b54612
103. Kooij JJS, Francken MH. DIVA 2.0 Diagnostic Interview Voor ADHD in Adults Bij Volwassenen [DIVA 2.0 Diagnostic Interview for ADHD in Adults]. DIVA Foundation; 2010.

104. Barkley RA, Murphy K. Attention Deficit Hyperactivity Disorder: A Clinical Workbook. 3rd ed. Guilford Press; 2006.

105. Wechsler D. Wechsler Abbreviated Scale of Intelligence (WASI). Harcourt Assessment; 1999.

106. Wechsler D. Wechsler Intelligence Scale for Children. 3rd ed. The Psychological Corporation; 1991.

107. Wechsler D. Wechsler Adult Intelligence Scale. 3rd ed. The Psychological Corporation; 1997.

108. Albrecht B, Brandeis D, Uebel H, et al. Familiality of neural preparation and response control in childhood attention deficit-hyperactivity disorder. Psychol Med. 2013;43:1997-2011. doi:10.1017/S003329171200270X

109. Doehnert M, Brandeis D, Straub M, Steinhausen HC, Drechsler R. Slow cortical potential neurofeedback in attention deficit hyperactivity disorder: is there neurophysiological evidence for specific effects? J Neural Transm. 2008;115:14 45-1456. doi:10.1007/s00702-008-0104-x

110. Kuntsi J, Wood AC, Rijsdijk F, et al. Separation of cognitive impairments in attention-deficit/hyperactivity disorder into 2 familial factors. Arch Gen Psychiatry. 2010;67:1159-1167. doi:10.1001/archgenpsychiatry.2010.139

111. Kuntsi J, Pinto R, Price TS, van der Meere JJ, Frazier-Wood AC, Asherson P. The separation of ADHD inattention and hyperactivity-impulsivity symptoms: pathways from genetic effects to cognitive impairments and symptoms. J Abnorm Child Psychol. 2014;42:127-136. doi:10.1007/s10802-013-9771-7

112. McLoughlin G, Asherson P, Albrecht B, et al. Cognitiveelectrophysiological indices of attentional and inhibitory processing in adults with ADHD: familial effects. Behav Brain Funct. 2011;7:26. doi:10.1186/1744-9081-7-26

113. Andreou P, Neale BM, Chen W, et al. Reaction time performance in ADHD: improvement under fast-incentive condition and familial effects. Psychol Med. 2007;37:1703-1715. doi:10.1017/ S0033291707000815

114. Uebel H, Albrecht B, Asherson P, et al. Performance variability, impulsivity errors and the impact of incentives as gender-independent endophenotypes for ADHD. J Child Psychol Psychiatry. 2010;51:210-218.

115. Valko L, Doehnert M, Muller UC, et al. Differences in neurophysiological markers of inhibitory and temporal processing deficits in children and adults with ADHD. $J$ Psychophysiol. 2009;23:235-246. doi:10.1027/0269-8803.23.4.235

116. Biederman J, Petty CR, Ball SW, et al. Are cognitive deficits in attention deficit/hyperactivity disorder related to the course of the disorder? A prospective controlled follow-up study of grown up boys with persistent and remitting course. Psychiatry Res. 2009;170:177-182. doi:10.1016/j.psychres.2008.09.010

117. McAuley T, Crosbie J, Charach A, Schachar R. The persistence of cognitive deficits in remitted and unremitted ADHD: a case for the state-independence of response inhibition. J Child Psychol Psychiatry Allied Discipl. 2014;55:292-300. doi:10.1111/jcpp.12160

118. Pazvantoğlu O, Aker AA, Karabekiroğlu K, et al. Neuropsychological weaknesses in adult ADHD: cognitive functions as core deficit and roles of them in persistence to adulthood. JINS. 2012;18:819-826. doi:10.1017/S1355617712000574

119. van Lieshout $M$, Luman M, Buitelaar J, Rommelse NNJ, Oosterlaan J. Does neurocognitive functioning predict future or persistence of ADHD? A systematic review. Clin Psychol Rev. 2013;33:539-560. doi:10.1016/j.cpr.2013.02.003

120. Bédard A-CV, Trampush JW, Newcorn JH, Halperin JM. Perceptual and motor inhibition in adolescents/young adults with childhood-diagnosed ADHD. Neuropsychology. 2010;24:4 24-434. doi:10.1037/a0018752 
121. Francx W, Oldehinkel M, Oosterlaan J, et al. The executive control network and symptomatic improvement in attention-deficit/hyperactivity disorder. Cortex. 2015;73:62-72. doi:10.1016/j.cortex.2015. 08.012

122. Cheung CHM, McLoughlin G, Brandeis D, Banaschewski T, Asherson P, Kuntsi J. Neurophysiological correlates of attentional fluctuation in attention-deficit/hyperactivity disorder. Brain Topogr. 2017;30(3):320-332. doi:10.1007/s10548-017-0554-2

123. Cheung $\mathrm{CH}$, Rijsdijk F, McLoughlin G, et al. Cognitive and neurophysiological markers of ADHD persistence and remission. Br J Psychiatry. 2016;208(6):548-555. doi:10.1192/ bjp.bp. 114.145185

124. Michelini G, Kitsune GL, Cheung CHM, et al. ADHD remission is linked to better neurophysiological error detection and attention-vigilance processes. Biol Psychiatry. 2016;15:923-932. doi:10.1016/j.biopsych.2016.06.021

125. James S-N, Cheung CHM, Rijsdijk F, Asherson P, Kuntsi J. Modifiable arousal in ADHD and its etiological association with fluctuating reaction times.. Biol Psychiatry Cogn Neurosci Neuroimag. 2016;1:539-547.

126. Zahn TP, Abate F, Little BC, Wender PH. Minimal brain dysfunction, stimulant drugs, and autonomic nervous system activity. Arch Gen Psychiatry. 1975;32:381-387. doi:10.1001/archpsyc.19 75.01760210115009

127. Conzelmann AB, Gerdes RF, Weyers MP, et al. hypoactivity in boys with attention-deficit/hyperactivity disorder and the influence of methylphenidate. World J Biol Psychiatry. 2014;15: 56-65. doi:10.3109/15622975.2013.829584

128. Mayer K, Wyckoff SN. Strehl U. Underarousal in adult ADHD: how are peripheral and cortical arousal related? Clin EEG Neurosci. 2016; 47:171-179.

129. Du Rietz E, Cheung $\mathrm{CH}$, McLoughlin G, et al. Self-report of ADHD shows limited agreement with objective markers of persistence and remittance. J Psychiatr Res. 2016;82:91-99. doi:10.1016/j.jpsychires.2016.07.020

130. Michelini G, Kitsune GL, Cheung CH, et al. Attention-deficit /hyperactivity disorder remission is linked to better neurophysiological error detection and attention-vigilance processes. Biol Psychiatry. 2016;80(12):923-932. doi:10.1016/j.biopsych.2016. 06.021

131. Yeung N, Cohen JD. The impact of cognitive deficits on conflict monitoring: predictable dissociations between the error-related negativity and N2. Psychol Sci. 2006;17:164-171. doi:10.1111/ j.1467-9280.2006.01680.x

132. Nieuwenhuis $\mathrm{S}$, Yeung $\mathrm{N}$, van den Wildenberg $\mathrm{W}$, Ridderinkhof KR. Electrophysiological correlates of anterior cingulate function in a go/no-go task: effects of response conflict and trial type frequency. Cogn Affect Behav Neurosci. 2003;3:17-26. doi:10.3758/CABN.3.1.17

133. Falkenstein M, Hielscher H, Dziobek I, et al. Action monitoring, error detection, and the basal ganglia: an ERP study. Neuroreport. 2001;12:157-161. doi:10.1097/00001756-200101 220-00039

134. Segalowitz SJ, Dywan J. Individual differences and developmental change in the ERN response: implications for models of ACC function. Psychol Res. 2009;73:857-870. doi:10.1007/s00426008-0193-z

135. Endrass T, Reuter B, Kathmann N. ERP correlates of conscious error recognition: aware and unaware errors in an antisaccade task. Eur J Neurosci. 2007;26:1714-1720. doi:10.1111/j.1460-956 8.2007.05785.x

136. Nieuwenhuis S, Ridderinkhof KR, Blom J, Band GP, Kok A. Error-related brain potentials are differentially related to awareness of response errors: evidence from an antisaccade task. Psychophysiology. 2001;38:752-760. doi:10.1111/1469-8986.38 50752
137. Albrecht B, Brandeis D, Uebel H, Heinrich $H$, Mueller UC, Hasselhorn M. Action monitoring in boys with attention-deficit/ hyperactivity disorder, their nonaffected siblings, and normal control subjects: evidence for an endophenotype. Biol Psychiatry. 2008;64:615-625. doi:10.1016/j.biopsych.2007.12. 016

138. McLoughlin G, Albrecht B, Banaschewski T, et al. Performance monitoring is altered in adult ADHD: a familial event-related potential investigation. Neuropsychologia. 2009;47:3134-3142. doi:10.1016/j.neuropsychologia.2009.07.013

139. Wild-Wall N, Oades RD, Schmidt-Wessels M, Christiansen H, Falkenstein M. Neural activity associated with executive functions in adolescents with attention-deficit/hyperactivity disorder (ADHD). Int J Psychophysiol. 2009;74:19-27.

140. Geburek AJ, Rist F, Gediga G, Stroux D, Pedersen A. Electrophysiological indices of error monitoring in juvenile and adult attention deficit hyperactivity disorder (ADHD) - A metaanalytic appraisal. Int $J$ Psychophysiol. 2013;87:349-362. doi:10.1016/j.ijpsycho.2012.08.006

141. Rodriguez PD, Baylis GC. Activation of brain attention systems in individuals with symptoms of ADHD. Behav Neurol. 2007;18 (2):115-130. doi:10.1155/2007/865717

142. McLoughlin G, Palmer JA, Rijsdijk F, Makeig S. Genetic overlap between evoked frontocentral theta-band phase variability, reaction time variability, and attention-deficit/hyperactivity disorder symptoms in a twin study. Biol Psychiatry. 2014;75:238-247. doi:10.1016/j.biopsych.2013.07.020

143. Bender S, Weisbrod M, Bornfleth H, Resch F, Oelkers-Ax R. How do children prepare to react? Imaging maturation of motor preparation and stimulus anticipation by late contingent negative variation. Neuroimage. 2005;27:737-752. doi:10.1016/j.neuroimage.2005. 05.020

144. Segalowitz SJ, Dywan J, Unsal A. Attentional factors in response time variability after traumatic brain injury: an ERP study. J Int Neuropsychol Soc. 1997;3:95-107. doi:10.1017/S1355617 797000957

145. Rommelse NN, Oosterlaan J, Buitelaar J, Faraone SV, Sergeant JA. Time reproduction in children with ADHD and their nonaffected siblings. J Am Acad Child Adolesc Psychiatry. 2007;46:582-590. doi:10.1097/CHI.0b013e3180335af7

146. Banaschewski T, Jennen-Steinmetz C, Brandeis D, et al. Neuropsychological correlates of emotional lability in children with ADHD. J Child Psychol Psychiatry. 2012;53:1139-1148. doi:10.1111/j.1469-7610.2012.02596.x

147. McLoughlin G, Albrecht B, Banaschewski $T$, et al. Electrophysiological evidence for abnormal preparatory states and inhibitory processing in adult ADHD. Behav Brain Funct. 2010;6:66. doi:10.1186/1744-9081-6-66

148. Overtoom CC, Bekker EM, van der Molen MW, et al. Methylphenidate restores link between stop-signal sensory impact and successful stopping in adults with attention-deficit/hyperactivity disorder. Biol Psychiatry. 2009;65:614-619. doi:10.1016/j. biopsych.2008.10.048

149. Pliszka SR. Pharmacologic treatment of attention-deficit/hyperactivity disorder: efficacy, safety and mechanisms of action. Neuropsychol Rev. 2007;17:61-72. doi:10.1007/s11065-0069017-3

150. Kratz O, Studer P, Baack J, et al. Differential effects of methylphenidate and atomoxetine on attentional processes in children with ADHD: an event-related potential study using the Attention Network Test. Prog Neuropsychopharmacol Biol Psychiatry. 2012;37:81-89. doi:10.1016/j.pnpbp.2011.12.008

151. Linssen AM, Vuurman EF, Sambeth A, et al. Contingent negative variation as a dopaminergic biomarker: evidence from dose-related effects of methylphenidate. Psychopharmacology (Berl). 2011;218:533-542. doi:10.1007/s00213-011-2345-x 
152. Wiersema R, van der Meere J, Antrop I, Roeyers H. State regulation in adult ADHD: an event-related potential study. J Clin Exp Neuropsychol. 2006;28:1113-1126. doi:10.1080/1380339050021 2896

153. Wiersema R, van der Meere J, Roeyers H, Van Coster R, Baeyens D. Event rate and event-related potentials in ADHD. J Child Psychol Psychiatry. 2006;47:560-567. doi:10.1111/j.1469-7610.2005.01592.x

154. Groom MJ, Scerif G, Liddle PF, et al. Effects of motivation and medication on electrophysiological markers of response inhibition in children with attention-deficit/hyperactivity disorder. Biol Psychiatry. 2010;67:624-631. doi:10.1016/j.biopsych.2009.09.029

155. Heinrich H, Gevensleben H, Freisleder FJ, Moll GH, Rothenberger A. Training of slow cortical potentials in attention-deficit/hyperactivity disorder: evidence for positive behavioral and neurophysiological effects. Biol Psychiatry. 2004;55:772-775. doi:10.1016/j.biopsych.2003.11.013

156. Wangler S, Gevensleben H, Albrecht B, et al. Neurofeedback in children with ADHD: specific event-related potential findings of a randomized controlled trial. Clin Neurophysiol. 2011;122: 942-950. doi:10.1016/j.clinph.2010.06.036

157. Doehnert M, Brandeis D, Schneider G, Drechsler R, Steinhausen HC. A neurophysiological marker of impaired preparation in an 11-year follow-up study of attention-deficit/hyperactivity disorder (ADHD). J Child Psychol Psychiatry. 2013;54:260-270. doi:10.1111/j.1469-7610.2012.02572.x

158. van den Berg B, Krebs RM, Lorist MM, Woldorff MG. Utilization of reward-prospect enhances preparatory attention and reduces stimulus conflict. Cogn Affect Behav Neurosci. 2014;14:561-577. doi:10.3758/s13415-014-0281-z

159. Ramchurn A, de Fockert JW, Mason L, Darling S, Bunce D. Intraindividual reaction time variability affects P300 amplitude rather than latency. Front Hum Neurosci. 2014;8:557. doi:10.3389/fnhum.2014.00557

160. Albaugh MD, Orr $\mathrm{C}$, Chaarani $\mathrm{B}$, et al. Inattention and reaction time variability are linked to ventromedial prefrontal volume in adolescents. Biol Psychiatry. 2017;82(9):660-668. doi:10.1016/j. biopsych.2017.01.003

161. Kofler MJ, Rapport MD, Sarver DE, et al. Reaction time variability in ADHD: a meta-analytic review of 319 studies. Clin Psychol Rev. 2013;33:795-811. doi:10.1016/j.cpr.2013.06.001

162. Stuss DT, Murphy KJ, Binns MA, Alexander MP. Staying on the job: the frontal lobes control individual performance variability. Brain. 2003;126:2363-2380. doi:10.1093/brain/awg237

163. Bellgrove MA, Hester R, Garavan H. The functional neuroanatomical correlates of response variability: evidence from a response inhibition task. Neuropsychologia. 2004;42:1910-1916. doi:10.10 16/j.neuropsychologia.2004.05.007

164. Egeland J. Frequency of attention deficit in first-episode schizophrenia compared to ADHD. Appl Neuropsychol. 2010;17: 125-134. doi:10.1080/09084280903297859

165. Thaler NS, Allen DN, Park BS, McMurray JC, Mayfield J. Attention processing abnormalities in children with traumatic brain injury and attention-deficit/hyperactivity disorder: differential impairment of component processes. J Clin Exp Neuropsychol. 2010;32:929-936. doi:10.1080/13803391003596488

166. Parasuraman R, Nestor P. Attention and driving. Assessment in Elderly Individuals with Dementia Clin Geriatr Med. 1993;9:377-387.

167. Uebel H, Albrecht B, Asherson P, et al. Performance variability, impulsivity errors and the impact of incentives as gender-independent endophenotypes for ADHD. $J$ Child Psychol Psychiatry. 2010;51:210-218.

168. Huang-Pollock CL, Mikami AY, Pfiffner L, McBurnett K. ADHD subtype differences in motivational responsivity but not inhibitory control: evidence from a reward-based variation of the stop signal paradigm. J Clin Child Adolesc Psychol. 2007;36:127-136. doi:10.1080/15374410701274124
169. Nigg JT. The ADHD response-inhibition deficit as measured by the stop task: replication with DSM-IV combined type, extension, and qualification. J Abnorm Child Psychol. 1999;27:393-402. doi:10.1023/A:1021980002473

170. Shanahan MA, Pennington BF, Willcutt EW. Do motivational incentives reduce the inhibition deficit in ADHD? Dev Neuropsychol. 2008;33:137-159. doi:10.1080/8756564070188 4238

171. Pasini A, Paloscia C, Alessandrelli R, Porfirio MC, Curatolo P. Attention and executive functions profile in drug naive ADHD subtypes. Brain Dev. 2007;29:400-408. doi:10.1016/j.braindev. 2006.11.010

172. Solanto MV, Gilbert SN, Raj A, et al. Neurocognitive functioning in $\mathrm{AD} / \mathrm{HD}$, predominantly inattentive and combined subtypes. J Abnorm Child Psychol. 2007;35:729-744. doi:10.1007/s1080 2-007-9123-6

173. Walhovd KB, Fjell AM. White matter volume predicts reaction time instability. Neuropsychologia. 2007;45:2277-2284. doi:10.1016/j.neuropsychologia.2007.02.022

174. Bunce D, Anstey KJ, Christensen H, Dear K, Wen W, Sachdev P. White matter hyperintensities and within-person variability in community-dwelling adults aged 60-64 years. Neuropsychologia. 2007;45:2009-2015. doi:10.1016/j.neuropsychologia.2007.02.006

175. Castellanos FX, Sonuga-Barke EJ, Scheres A, Martino A, Hyde C, Walters JR. Varieties of attention-deficit/hyperactivity disorder-related intra-individual variability. Biol Psychiatry. 2005;57:1416-1423. doi:10.1016/j.biopsych.2004.12.005

176. Epstein JN, Brinkman WB, Froehlich T, et al. Effects of stimulant medication, incentives, and event rate on reaction time variability in children with ADHD. Neuropsychopharmacology. 2011;36:1060-1072. doi:10.1038/npp.2010.243

177. Spencer SV, Hawk LW, Richards JB, Shiels K, Pelham WE, Waxmonsky JG. Stimulant treatment reduces lapses in attention among children with ADHD: the effects of methylphenidate on intra-individual response time distributions. $J$ Abnorm Child Psychol. 2009;37:805-816. doi:10.1007/s10802-009-9316-2

178. Boonstra AM, Kooij JJ, Oosterlaan J, Sergeant JA, Buitelaar JK. Does methylphenidate improve inhibition and other cognitive abilities in adults with childhood-onset ADHD? J Clin Exp Neuropsychol. 2005;27:278-298. doi:10.1080/13803390490515757

179. Rosa-Neto P, Lou HC, Cumming P, et al. Methylphenidate-evoked changes in striatal dopamine correlate with inattention and impulsivity in adolescents with attention deficit hyperactivity disorder. Neuroimage. 2005;25:868-876. doi:10.1016/j.neuroimage.2004.11. 031

180. Fitzpatrick PA, Klorman R, Brumaghim JT, Borgstedt AD. Effects of sustained-release and standard preparations of methylphenidate on attention deficit disorder. J Am Acad Child Adolesc Psychiatry. 1992;31:226-234. doi:10.1097/00004583-19920300000008

181. Teicher MH, Lowen SB, Polcari A, Foley M, McGreenery CE. Novel strategy for the analysis of CPT data provides new insight into the effects of methylphenidate on attentional states in children with ADHD. J Child Adolesc Psychopharm. 2004;14: 219-232. doi:10.1089/1044546041648995

182. Tannock R, Schachar R, Logan G. Methylphenidate and cognitive flexibility: dissociated dose effects in hyperactive children. J Abnorm Child Psychol. 1995;23:235-266. doi:10.1007/BF01 447091

183. Epstein JN, Conners CK, Hervey AS, et al. Assessing medication effects in the MTA study using neuropsychological outcomes. J Child Psychol Psychiatry. 2006;47:446-456. doi:10.1111/ j.1469-7610.2005.01469.x

184. Epstein JN, Tsal Y. Evidence for cognitive training as a treatment strategy for children with attention-deficit/hyperactivity disorder. J ADHD Relat Disord. 2010;1:49-64. 
185. Tamm L, McCandliss BD, Liang A, Wigal TL, Posner MI, Swanson JM. Can Attention Itself Be Trained? Attention Training for Children at Risk for ADHD. Attention Deficit/ Hyperactivity Disorder: Concepts, Controversies, New Directions. New York: Informa Healthcare; 2007:399-411.

186. Lutz A, Slagter HA, Rawlings NB, Francis AD, Greischar LL, Davidson RJ. Mental training enhances attentional stability: neural and behavioral evidence. Neurosci. 2009;29:13418-13427. doi:10.1523/JNEUROSCI.1614-09.2009

187. Scarpelli S, Gorgoni M, D'Atri A, Reda F, De Gennaro L. Advances in understanding the relationship between sleep and Attention Deficit-Hyperactivity Disorder (ADHD). J Clin Med. 2019;8(10):E1737. doi:10.3390/jcm8101737

188. Bussalb A, Congedo M, Barthélemy Q, et al. Clinical and experimental factors influencing the efficacy of neurofeedback in ADHD: a meta-analysis. Front Psychiatry. 2019;10:35. doi:10.3389/fpsyt.2019.00035

189. Van Doren J, Arns M, Heinrich H, Vollebregt MA, Strehl U, Loo K. Sustained effects of neurofeedback in ADHD: a systematic review and meta-analysis. Eur Child Adolesc Psychiatry. 2019;28(3):293-305. doi:10.1007/s00787-018-1121-4

190. Lau-Zhu A, Tye C, Rijsdijk F, McLoughlin G. No evidence of associations between ADHD and event-related brain potentials from a continuous performance task in a population-based sample of adolescent twins. PLoS One. 2019;14(10):e0223460. doi:10.1371/journal.pone. 0223460

191. Ogrim G, Kropotov JD. Predicting clinical gains and side effects of stimulant medication in pediatric attention-deficit/hyperactivity disorder by combining measures from qEEG and ERPs in a Cued GO/NOGO task. Clin EEG Neurosci. 2019;50(1):34-43. doi: $10.1177 / 1550059418782328$

192. Song DH, Shin DW, Jon DI, Ha EH. Effects of methylphenidate on quantitative EEG of boys with attention-deficit hyperactivity disorder in continuous performance test. Yonsei Med J. 2005;46 (1):34-41. doi:10.3349/ymj.2005.46.1.34

193. Rapport MD, Kelly KL. Psychostimulant effects on learning and cognitive function: findings and implication for children with attention deficit hyperactivity disorder. Clin Psychol Rev. 1991;11:61-92. doi:10.1016/0272-7358(91)90138-K

194. Coon HW, Klorman R, Borgstedt AD. Effects of methylphenidate on adolescents with a childhood history of attention deficit disorder: II. Information processing. $J$ Am Acad Child Adolesc Psychiatry. 1987;26:368-374. doi:10.1097/00004583-198705000-00016

195. Garfinkel BD, Brown WA, Klee SH, Braden W, Beauchesne H, Shapiro SK. Neuroendocrine and cognitive responses to amphetamine in adolescents with a history of attention deficit disorder. $J$ Am Acad Child Adolesc Psychiatry. 1986;25:503-508. doi:10.1016/S0002-7138(10)60009-X

196. Greenberg LM, Waldman ID. Developmental normative data on the Test of Variables of Attention (TOVA). J Child Psychol Psychiatry. 1993;34:1019-1030.

197. Moreno-García I, Delgado-Pardo G, Camacho-vara de Rey C, Meneres-Sancho S, Servera-Barceló M. Neurofeedback, pharmacological treatment and behavioral therapy in hyperactivity: multilevel analysis of treatment effects on electroencephalography. Int J Clin Health Psychol. 2015;15(3):217-225. doi:10.1016/j. ijchp.2015.04.003

198. Barkley RB. Defiant Children: A Clinician Manual for Parent Training. New York: Guilford Press; 1987.

199. Woltering S, Jung J, Liu Z, Tannock R. Resting state EEG oscillatory power differences in ADHD college students and their peers. Behav Brain Funct. 2012;8:60. doi:10.1186/17449081-8-60

200. Jasper H, Solomon P, Bradley C. Electroencephalographic analyses of behavior problem children. Am J Psychiatry. 1938;95: 641. doi:10.1176/ajp.95.3.641
201. Satterfield JH, Lesser LI, Saul RE, Cantwell DP. EEG aspects in the diagnosis and treatment of minimal brain dysfunction. Ann NY Acad Sci. 1973;205:274-282. doi:10.1111/j.1749-6632.1973. tb43185.x

202. Monastra VJ, Lubar JF, Linden M. The development of a quantitative electroencephalographic scanning process for attention deficit-hyperactivity disorder: reliability and validity studies. Neuropsychology. 2001;15:136-144. doi:10.1037/0894-4105.15. 1.136

203. Williams LM, Hermens DF, Thein T, et al. Using brain-based cognitive measures to support clinical decisions in ADHD. Pediatr Neurol. 2010;42:118-126. doi:10.1016/j.pediatrneurol. 2009.08.010

204. Van Dongen-boomsma M, Lansbergen MM, Bekker EM, et al. Relation between resting EEG to cognitive performance and clinical symptoms in adults with attention-deficit/hyperactivity disorder. Neurosci Lett. 2010;469:102-106. doi:10.1016/j.neulet. 2009.11.053

205. Ogrim G, Kropotov J, Hestad K. The quantitative EEG theta/beta ration in attention deficit/hyperactivity disorder and normal controls: sensitivity, specificity, and behavioral correlates. Psychiatry Res. 2012;198:482-488. doi:10.1016/j.psychres.2011.12.041

206. Buyck I, Wieserma JR. Resting electroencephalogram in attention deficit hyperactivity disorder: developmental course and diagnostic value. Psychiatry Res. 2014;216:391-397. doi:10.1016/j. psychres.2013.12.055

207. Arns M, Loo SK, Sterman MB, et al. Editorial Perspective: how should child psychologists and psychiatrists interpret FDA device approval? Caveat emptor. J Child Psychol Psychiatr. 2016;57: 656-658. doi:10.1111/jcpp. 12524

208. The Department of Health \& Human Services, Food and Drug Administration. Letter to NEBA Health, LLC. Re: K112711 Neuropsychiatric EEG-based assessment aid for ADHD (NEBA) System. 2013. Available from: https://www.accessdata.fda.gov/ cdrh_docs/pdf11/K112711.pdf.

209. Verbaten MN, Overtoom CCE, Koelega HS, et al. Methylphenidate influences on both early and late ERP waves of ADHD children in a continuous performance test. $J$ Abnorm Child Psychol. 1994;22:561-578. doi:10.1007/BF02168938

210. Winsberg BG, Javitt DC, Shanahan Silipo G. Electrophysiological indices of information processing in methylphenidate responders. Biol Psychiatry. 1997;42:434-445. doi:10.1016/S0006-3223(96) 00429-5

211. US Department of Health and Human Services. FDA approval letter for NEBA System. Available from. fda.gov/cdrh_docs/ pdf11/K112711.pdf. Accessed April 2, 2020.

212. FDA. 2013. De Novo Classification Request for Neuropsychiatric EEG-Based Assessment Aid for ADHD (NEBA) SystemK112711, July $15 ; 2013$.

213. Gloss D, Varma JK, Pringsheim T, Nuwer MR. Practice advisory: the utility of EEG theta/beta power ratio in ADHD diagnosis: report of the guideline development, dissemination, and implementation subcommittee of the American Academy of Neurology. Neurology. 2016;87(22):2375-2379.

214. Lenartowicz A, Loo SK. Use of EEG to diagnose ADHD. Curr Psychiatry Rep. 2014;16(11):498. doi:10.1007/s11920-0140498-0

215. Loo SK, Cho A, Hale TS, McGough J, McCracken J, Smalley SL. Characterization of the theta to beta ratio in ADHD: identifying potential sources of heterogeneity. $J$ Atten Disord. 2013;17(5):384-392. doi:10.1177/1087054712468050 Epub 2012 Dec 20.

216. Liechti MD, Valko L, Müller UC, et al. Diagnostic value of resting electroencephalogram in attention-deficit/hyperactivity disorder across the lifespan. Brain Topogr. 2013;26(1):135-151. doi:10.1007/s10548-012-0258-6 Epub 2012 Oct 9. 
217. Petersen IT, Hoyniak CP, Bates JE, Staples AD, Molfese DL. A longitudinal, within-person investigation of the association between the P3 ERP component and externalizing behavior problems in young children. J Child Psychol Psychiatry. 2018;59 (10):1044-1051. doi:10.1111/jcpp. 12975

218. Szuromi B, Czobor P, Komlosi S, Bitter I. P300 deficits in adults with attention deficit hyperactivity disorder: a meta-analysis. Psychol Med. 2011;41:1529-1538. doi:10.1017/S0033291710001996

219. Seidman LJ, Valera EM, Makris N. Structural brain imaging of attention-deficit/hyperactivity disorder. Biol Psychiatry. 2005;57:1263-1272. doi:10.1016/j.biopsych.2004.11.019

220. Corbetta M, Patel G, Shulman GL. The reorienting system of the human brain: from environment to theory of mind. Neuron. 2008. doi:10.1016/j.neuron.2008.04.017

221. Casey BJ, Jones RM, Hare TA. The adolescent brain. Ann N Y Acad Sci. 2008;1124:111-126. doi:10.1196/annals.1440.010

222. Polich J. Updating P300: an integrative theory of P3a and P3b. Clin Neurophysiol. 2007;118:2128-2148. doi:10.1016/j. clinph.2007.04.019 PubMed: 17573239.

223. Hoyniak CP, Petersen IT, McQuillan ME, Staples AD, Bates JE. Less efficient neural processing related to irregular sleep and less sustained attention in toddlers. Dev Neuropsychol. 2015;40(3):155-166. doi:10.1080/87565641.2015.1016162 PubMed: 26151613.

224. Johnstone SJ, Barry RJ, Clarke AR. Ten years on: a follow-up review of ERP research in attention-deficit/hyperactivity disorder. Clin Neurophysiol. 2013;124:644657. doi:10.1016/j.clinph.2012.09.006

225. van Dinteren R, Arns M, Jongsma MLA, Kessels RPC. P300 development across the lifespan: a systematic review and meta-analysis. PLoS One. 2014;9:e87347. doi:10.1371/journal. pone.0087347 PubMed: 24551055.

226. Friedman D, Cycowicz YM, Gaeta H. The novelty P3: an eventrelated brain potential (ERP) sign of the brain's evaluation of novelty. Neurosci Biobehav Rev. 2001;25:355-373. doi:10.1016/ S0149-7634(01)00019-7 PubMed: 11445140.

227. Hermens DF, Ward PB, MAR H, Kaur M, Naismith SL, Hickie IB. Impaired MMN/P3a complex in first-episode psychosis: cognitive and psychosocial associations. Prog Neuropsychopharmacol Biol Psychiatry. 2010;34:822-829. doi:10.1016/j.pnpbp.2010.03.019 PubMed: 20302901.

228. Dodge KA, Crick NR. Social information-processing bases of aggressive behavior in children. Pers Soc Psychol Bull. 1990;16:8-22. doi:10.1177/0146167290161002

229. Iacono WG, Malone SM. Developmental endophenotypes: indexing genetic risk for substance abuse with the P300 brain event-related potential. Child Dev Perspect. 2011;5:239-247. doi:10.1111/j.1750-8606.2011.00205.x

230. Gao Y, Raine A. P3 event-related potential impairments in antisocial and psychopathic individuals: A meta-analysis. Biol Psychol. 2009;82:199-210. doi:10.1016/j.biopsycho.2009.06.006

231. Pasion R, Fernandes C, Pereira MR, Barbosa F. Antisocial behaviour and psychopathy: uncovering the externalizing link in the P3 modulation. Neurosci Biobehav Rev. 2018;91:170-186. doi:10.1016/j.neubiorev.2017.03.012

232. van Beijsterveldt CEM, van Baal GCM. Twin and family studies of the human electroencephalogram: a review and a meta-analysis. Biol Psychol. 2002;61:111-138. doi:10.1016/S0301-0511(02)00055-8

233. Hicks BM, Bernat E, Malone SM, et al. Genes mediate the association between P3 amplitude and externalizing disorders. Psychophysiology. 2007;44:98-105. doi:10.1111/j.1469-8986.2006.00471.x

234. Pogarell O, Padberg F, Karch S, et al. Dopaminergic mechanisms of target detection - P300 event related potential and striatal dopamine. Psychiatry Res. 2011;194:212-218. doi:10.1016/j. pscychresns.2011.02.002

235. Soltani M, Knight RT. Neural origins of the P300. Crit Rev Neurobiol. 2000;14:199-224. doi:10.1615/CritRevNeurobiol. v14.i3-4.20
236. Gatzke-Kopp LM, Beauchaine TP, Shannon KE, et al. Neurological correlates of reward responding in adolescents with and without externalizing behavior disorders. $J$ Abnorm Psychol. 2009;118:203-213. doi:10.1037/a0014378 PubMed: 19222326.

237. Aasen IE, Øgrim G, Kropotov J, Brunner JF. Methylphenidate selectively modulates one sub-component of the no-go P3 in pediatric ADHD medication responders. Biol Psychol. 2018;134:30-38. doi:10.1016/j.biopsycho.2018.02.011 Epub 20 18 Feb 21.

238. Heinrich H, Grunitz J, Stonawski V, et al. Attention, cognitive control and motivation in ADHD: linking event-related brain potentials and DNA methylation patterns in boys at early school age. Sci Rep. 2017;7(1):3823. doi:10.1038/s41598-017-03326-3

239. Baijot S, Cevallos C, Zarka D, et al. EEG dynamics of a go/nogo task in children with ADHD. Brain Sci. 2017;7(12):E167. doi:10.3390/brainsci7120167

240. Petersen IT, Hoyniak CP, Bates JE, Staples AD, Molfese DL. A longitudinal, within-person investigation of the association between the P3 ERP component and externalizing behavior problems in young children. J Child Psychol Psychiatry. 2018;59 (10):1044-1051. doi:10.1111/jcpp. 12975

241. Chronaki G, Soltesz F, Benikos N, Sonuga-Barke EJS. An electrophysiological investigation of reinforcement effects in attention deficit/hyperactivity disorder: dissociating cue sensitivity from down-stream effects on target engagement and performance. Dev Cogn Neurosci. 2017;28:12-20. doi:10.1016/j.den.2017.10. 003

242. Arns M, Conners CK, Kraemer HC. A decade of EEG theta/Beta ratio research in ADHD: a meta-analysis. $J$ Atten Disord. 2013;17:374-383. doi:10.1177/1087054712460087

243. Van der Heijden KB, Smits MG, Van Someren EJW, Gunning WB. Idiopathic chronic sleep onset insomnia in attention-deficit/hyperactivity disorder: a circadian rhythm sleep disorder. Chronobiol Int. 2005;22:559-570. doi:10.1081/cbi200062410

244. Van Dongen HPA, Maislin G, Mullington JM, Dinges DF. The cumulative cost of additional wakefulness: dose-response effects on neurobehavioral functions and sleep physiology from chronic sleep restriction and total sleep deprivation. Sleep. 2003;26: 117-126. doi:10.1093/sleep/26.2.117

245. Cortese S, Brown TE, Corkum P, et al. Assessment and management of sleep problems in youths with attention-deficit/hyperactivity disorder. J Am Acad Child Adolesc Psychiatry. 2013;52: 784-796. doi:10.1016/j.jaac.2013.06.001

246. Rybak YE, McNeely HE, Mackenzie BE, Jain UR, Levitan RD. Seasonality and circadian preference in adult attention-deficit/ hyperactivity disorder: clinical and neuropsychological correlates. Compr Psychiatry. 2007;48:562-571. doi:10.1016/j. comppsych.2007.05.008

247. Hoedlmoser K, Pecherstorfer T, Gruber G, et al. Instrumental conditioning of human sensorimotor rhythm (12-15 hz) and its impact on sleep as well as declarative learning. Sleep. 2008; 31:1401-1408.

248. Cortoos A, De Valck E, Arns M, Breteler MHM, Cluydts R. An exploratory study on the effects of tele-neurofeedback and tele-biofeedback on objective and subjective sleep in patients with primary insomnia. Appl Psychophysiol Biofeedback. 2010;35:125-134. doi:10.1007/s10484-009-9116-z

249. Dijk D-J, Roth C, Landolt H-P, et al. Melatonin effect on daytime sleep in men: suppression of EEG low frequency activity and enhancement of spindle frequency activity. Neuroscience Letters. 1995;201(1):13-16. doi:10.1016/0304-3940(95)12118-n

250. De Gennaro L, Ferrara M. Sleep spindles: an overview. Sleep Med Rev. 2003;7:423-440. doi:10.1053/smrv.2002.0252 
251. Newson JJ, Thiagarajan TC. EEG frequency bands in psychiatric disorders: a review of resting state studies. Front Hum Neurosci. 2019;12:521. doi:10.3389/fnhum.2018.00521

252. Flint J, Munafò MR. The endophenotype concept in psychiatric genetics. Psychol Med. 2007;37(2):163-180. doi:10.1017/S003 3291706008750
253. Boomsma DI, Saviouk V, Hottenga JJ, et al. Genetic epidemiology of attention deficit hyperactivity disorder (ADHD index) in adults. PLoS One. 2010;5(5):e10621. doi:10.1371/journal.pone.0 010621

\section{Publish your work in this journal}

Medical Devices: Evidence and Research is an international, peerreviewed, open access journal that focuses on the evidence, technology, research, and expert opinion supporting the use and application of medical devices in the diagnosis, monitoring, treatment and management of clinical conditions and physiological processes. The identification of novel devices and optimal use of existing devices which will lead to improved clinical outcomes and more effective patient management and safety is a key feature of the journal. The manuscript management system is completely online and includes a very quick and fair peer-review system. Visit http:// www.dovepress.com/testimonials.php to read real quotes from published authors. 